\title{
Inverse Hydrogen Migration in Arginine-Containing Peptide Ions upon Electron Transfer
}

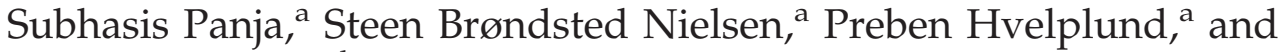 \\ František Tureček ${ }^{\mathrm{b}}$ \\ ${ }^{a}$ Department of Physics and Astronomy, University of Aarhus, Denmark \\ ${ }^{\mathrm{b}}$ Department of Chemistry, University of Washington, Seattle, Washington, USA
}

Collisional electron transfer from gaseous Cs atoms was studied for singly and doubly protonated peptides Gly-Arg (GR) and Ala-Arg (AR) at 50- and 100-keV kinetic energies. Singly protonated GR and AR were discharged to radicals that in part rearranged by migration of a $\mathrm{C}_{\alpha}$ hydrogen atom onto the guanidine group. The $\mathrm{C}_{\alpha}$-radical isomers formed were detected as stable anions following transfer of a second electron. In addition to the stabilizing rearrangements, the radicals underwent side-chain and backbone dissociations. The latter formed $\mathrm{z}$ fragments that were detected as the corresponding anions. Analysis of the (GR $+\mathrm{H}$ ) radical potential energy surface using electronic structure theory in combination with Rice-Ramsperger-Kassel-Marcus calculations of rate constants indicated that the arginine $\mathrm{C}_{\alpha}$ hydrogen atom was likely to be transferred to the arginine side-chain on the experimental timescale of $\leq 200 \mathrm{~ns}$. Transfer of the Gly $\mathrm{C}_{\alpha}-\mathrm{H}$ was calculated to have a higher transitionstate energy and was not kinetically competitive. Collisional electron transfer to doubly protonated GR and AR resulted in complete dissociation of $(\mathrm{GR}+2 \mathrm{H})^{+\cdot}$ and $(\mathrm{AR}+2 \mathrm{H})^{+\cdot}$ ions by loss of $\mathrm{H}$, ammonia, and $\mathrm{N}-\mathrm{C}_{\alpha}$ bond cleavage. Electronic structure theory analysis of $(\mathrm{GR}+2 \mathrm{H})^{+\cdot}$ indicated the presence of multiple conformers and electronic states that differed in reactivity and steered the dissociations to distinct channels. Electron attachment to (GR + $2 \mathrm{H})^{2+}$ resulted in the formation of closely spaced electronic states of $(\mathrm{GR}+2 \mathrm{H})^{+\cdot}$ in which the electron density was delocalized over the guanidinium, ammonium, amide, and carboxyl groups. The different behavior of $(\mathrm{GR}+\mathrm{H})^{-}$and $(\mathrm{GR}+2 \mathrm{H})^{+\cdot}$ is explained by the different timescales for dissociation and different internal energies acquired upon electron transfer. (J Am Soc Mass Spectrom 2008, 19, 1726-1742) () 2008 Published by Elsevier Inc. on behalf of American Society for Mass Spectrometry

A rginine frequently occurs as a C-terminal residue in tryptic peptides used in bottom-up proteomics. Because of the high basicity of the guanidine group in the side chain, arginine residues at C-termini are invariably protonated in peptide ions produced by electrospray ionization. The ability of arginine to sequester a proton in the gas-phase peptide ion has a major effect on charge-driven ion dissociations induced by collisional activation [1].

Less is known about the effects that Arg residues have on dissociations of charge-reduced peptide ions produced by electron capture or transfer [2]. For example, protonated Arg residues at C-termini have been reported to undergo preferential reduction upon electron capture and the dissociations mainly formed ion fragments that carried the remaining charge on the N-terminal Arg residue [3]. Recently, we have studied one-electron reduction of protonated arginine and argi-

Address reprint requests to Dr. František Tureček, University of Washington, Department of Chemistry, Bagley Hall, Box 351700, Seattle, WA 98195-1700. E-mail: turecek@chem.washington.edu nine amide as model systems for related electron capture (ECD) [4] and electron-transfer dissociations (ETD) [5] of arginine-terminated peptides. Reduction of protonated functional groups in gas-phase peptide ions produces transient radical intermediates that have been considered to donate hydrogen atoms to amide carbonyl groups and thus initiate dissociations of backbone $\mathrm{N}-\mathrm{C}_{\alpha}$ bonds, resulting in the formation of $c$ and $z$ sequence ions [4]. However, we have found for both arginine and arginine amide that the protonated guanidine group, when converted to a guanidinium radical, was an inefficient donor of hydrogen atoms [6]. In contrast, the guanidinium carbon atom radicals were found to be good hydrogen atom acceptors [7] in transfers of hydrogen atoms from the amino acid $\mathrm{C}_{\alpha}$ positions forming stable $C_{\alpha}$ radicals. Amino acid and peptide $C_{\alpha}$ radicals have also been of much interest as reactive intermediates of protein radiation damage and also in connection with radical enzyme reactions [8]. Regarding gas-phase reactions, arginine $C_{\alpha}$ radicals have been calculated at high levels of ab initio theory to be thermodynamically more stable than guanidinium
(C) 2008 Published by Elsevier Inc. on behalf of American Society for Mass Spectrometry. $1044-0305 / 08 / \$ 32.00$

doi:10.1016/j.jasms.2008.08.001
Published online August 9, 2008 Received June 29, 2008 Revised August 1, 2008 Accepted August 4, 2008 
radicals originally produced by electron transfer to protonated arginine $[7,9]$. The tendency for kinetically favored inverse, $\mathrm{C}_{\alpha}-\mathrm{H} \rightarrow \mathrm{C}$ (guanidine), migration was called the arginine anomaly [9] because it indicated that the guanidine radical group was a poor hydrogen atom donor and might not be involved in triggering backbone $\mathrm{N}-\mathrm{C}_{\alpha}$ bond dissociations in arginine-containing peptides. The theoretically predicted intermediate arginine $C_{\alpha}$ radicals were recently detected as stable anions after electron transfer from Cs atoms [6].

We now report additional evidence for inverse hydrogen atom migrations in arginine-containing peptide ions. Whereas the previous studies [6,9] used ions and radicals derived from amino acids, we now use singly and doubly protonated dipeptide ions $(\mathrm{GR}+\mathrm{H})^{+},(\mathrm{AR}+\mathrm{H})^{+},(\mathrm{GR}+$ $2 \mathrm{H})^{2+}$, and $(\mathrm{AR}+2 \mathrm{H})^{2+}$ that are fully or partially discharged by collisions with Cs atoms. In contrast to ECD and ETD, the timescale for the electron-transfer collision in our experiments is in the low-femtosecond range, which secures that the charge-reduced species is initially formed with the geometry of the precursor cation. Dissociations or rearrangements of the chargereduced intermediates are observed on a 100-ns to $5-\mu \mathrm{s}$ timescale. This allows us to study much faster processes than those amenable to ECD and ETD measurements. The dipeptide systems are then used to compare electron distribution in radicals or cation-radicals following reduction of the arginine side chain with that in structurally related peptide cation-radicals where the unpaired electron can be delocalized over remote functional groups [10]. The size of the current dipeptide systems (34-38 atoms) further allows us to complement experiments with high-level ab initio calculations for precursor ions, radicals, cation-radicals, transition states, and dissociation products that use electroncorrelation methods with large basis sets to achieve a reliable description of the electronic properties and energetics.

\section{Experimental}

\section{Materials and Methods}

Ala-Arg and Gly-Arg (a gift from Dr. Julia ChamotRooke, Laboratory of Organic Reaction Mechanisms, Ecole Polytechnique, Palaiseau, France) were purchased from Sigma-Aldrich (Saint Quentin Fallavier, France) and used as received. Electron-capture-induced dissociation (ECID) and charge reversal $\left({ }^{+} \mathrm{CR}^{-}\right)$mass spectra were measured on a large-scale sector instrument described previously [11]. Ions were produced by electrospray ionization from 1:1 water/methanol solutions containing $1 \%$ of acetic acid. Precursor $(\mathrm{GR}+\mathrm{H})^{+}$and $(\mathrm{AR}+\mathrm{H})^{+}$singly charged ions were accelerated to 50 $\mathrm{keV}$ corresponding to velocities of 2.04 and $1.98 \times 10^{5} \mathrm{~m} \mathrm{~s}^{-1}$, respectively. Doubly charged $(\mathrm{GR}+2 \mathrm{H})^{2+}$ and $(\mathrm{AR}+$ $2 \mathrm{H})^{2+}$ precursor ions were produced under the same conditions and accelerated to $100 \mathrm{keV}$ corresponding to ion velocities of 2.88 and $2.79 \times 10^{5} \mathrm{~m} \mathrm{~s}^{-1}$, respectively.
Deuterated precursor ions were produced by electrospray from $\mathrm{D}_{2} \mathrm{O} / \mathrm{CH}_{3} \mathrm{OD}$ solutions while saturating the ionizer space with $\mathrm{D}_{2} \mathrm{O}$ vapor. The desired ions from electrospray were mass selected by a magnetic sector at mass resolution $>500$ and subjected to collisions with Cs vapor in a special cell. For ECID measurements, the temperature in the cell was maintained at $80-85^{\circ} \mathrm{C}$ to allow mainly single-ion collisions with Cs. For ${ }^{+} \mathrm{CR}^{-}$ measurements, the temperature in the cell was maintained at $105^{\circ} \mathrm{C}$ to allow two consecutive ion-Cs collisions. The ion drift times through the 4-cm-long collision cell were, respectively, $t \approx 200$ and 140 ns for the singly and doubly charged peptide ions under study. During the passage through the cell, the doubly charged ions underwent one collision with Cs atoms and the charge-reduced positively charged products were separated by kinetic energy in a hemispheric electrostatic analyzer and detected by ion counting. Singly charged peptide ions were discharged by a collision with Cs to form radicals that had a Poisson distribution of drift times before being ionized to anions in a second collision. The distribution peaks at $t / 2 \approx$ $100 \mathrm{~ns}$, which represents the most probable radical lifetime [6]. Negative ions formed in the cell were allowed to drift to a hemispheric electrostatic analyzer, where they were separated by kinetic energy and detected. Multiple scans were taken and averaged to obtain sufficient ion counts for most negative ions. ECID spectra of $(\mathrm{AR}+2 \mathrm{H})^{2+}$ ions were also measured with a narrow $(0.1 \mathrm{~mm})$ electrostatic energy analyzer (ESA) entrance slit for increased kinetic energy and mass resolution.

\section{Calculations}

Standard ab initio calculations were performed using the Gaussian 03 suite of programs [12]. Ion and radical structures were first optimized with density functional theory calculations using the B3LYP hybrid functional [13] and the $6-31+G(d, p)$ basis set, and the local energy minima and transition states were characterized by harmonic frequency analysis to have the appropriate number of imaginary frequencies (zero for local minima and one for transition states). The calculated harmonic frequencies were scaled by 0.963 [14]. The structures were then reoptimized with B3LYP/6-31++G(d,p). Improved energies were obtained by single-point calculations on the B3LYP/6-31++G(d,p)-optimized geometries. The single-point calculations used B3LYP and Møller-Plesset perturbational theory [15] truncated at second-order with valence electrons only excitations [MP2(frozen core)] and the $6-311++\mathrm{G}(2 \mathrm{~d}, \mathrm{p})$ basis set. For a few selected systems we also obtained B3LYP and MP2 single-point energies with the larger 6-311++G(3df,2p) and aug-cc-pVTZ basis sets. For molecular systems of the $(\mathrm{GR}+2 \mathrm{H})^{+\cdot}$ cation-radical size these basis sets comprised 843, 1144, and 1654 primitive gaussians, respectively. Spin-unrestricted formalism was used for calculations of open-shell systems. Contamination by higher 
spin states was modest, as judged from the expectation values of the spin operator $\left\langle\mathrm{S}^{2}\right\rangle$ that were $\leq 0.76$ for UB3LYP and $\leq 0.78$ for UMP2 calculations for most radicals. The UMP2 energies were corrected by spin annihilation [16] that reduced the $\left\langle S^{2}\right\rangle$ to close to the theoretical value for a pure doublet state $(0.75)$. The single-point B3LYP and spin-projected MP2 energies were averaged according to the B3-PMP2 procedure [17] that resulted in cancellation of small errors inherent to both approximations and provided dissociation and transition-state energies of improved accuracy, as previously shown for a number of closed-shell and openshell systems [18]. The B3-PMP2 correction scheme finds a theoretical background in the analysis of bond dissociation in $\mathrm{H}_{2}$, where B3LYP was found to overestimate the correlation energy, whereas MP2 underestimated it by the same amount when compared to full-configuration interaction (CI) reference calculations [19]. Excited-state energies were calculated for optimized ion and radical geometries using time-dependent density functional theory (TD-DFT) with the B3LYP functional and $6-311++G(2 d, p)$ basis set [20]. The use of TD-DFT for open-shell electronic systems is justified for ammonium and other peptide radicals where the singly occupied molecular orbital (SOMO)-ion energy gap (recombination energy) is typically smaller than excitation energies for valence electrons in underlying doubly occupied molecular orbitals. For low excited states at least, this ensures single-electron excitations from the SOMO to a linear combination of virtual orbitals to provide poles of the response functions [20]. This is readily checked in the Gaussian output of a TD calculation, where all excitations should be of the $\alpha(\mathrm{SOMO}) \rightarrow \alpha$ (virtual orbital) type. The molecular orbitals for the excited states were obtained as linear combinations of virtual orbitals using the TD-B3LYP/ $6-311++G(2 d, p)$ expansion coefficients. Atomic spin and charge densities were calculated using the natural population analysis (NPA) method [21].

Unimolecular rate constants were calculated by the Rice-Ramsperger-Kassel-Marcus (RRKM) [22] theory using Hase's program [23] that was recompiled in $\mathrm{C}++$ and run under Windows XP [24] The RRKM rate constants were obtained by direct count of quantum states at internal energies that were increased in $2 \mathrm{~kJ}$ $\mathrm{mol}^{-1}$ steps from the transition state up to about $300 \mathrm{~kJ}$ $\mathrm{mol}^{-1}$ above the reactant. Rotations were treated adiabatically and the calculated $k(E, J, K)$ microscopic rate constants were Boltzmann-averaged over the thermal distribution of rotational states at $298 \mathrm{~K}$.

\section{Results}

ECID Spectra of $(G R+2 H)^{2+}$ and $(A R+2 H)^{2+}$

The ECID spectrum of $(\mathrm{GR}+2 \mathrm{H})^{2+}(m / z$ 116.5, Figure 1$)$ shows several fragment ions, whereas the chargereduced $(\mathrm{GR}+2 \mathrm{H})^{+\cdot}$ ion at $m / z 233$ is not detected ( $<1 \%$ of $m / z 232$ intensity, Figure 1, inset). The dissociation products were identified by mass shifts arising from Gly/Ala substitution and deuterium labeling in AR. The three major dissociations of $(\mathrm{GR}+2 \mathrm{H})^{+\cdot}$ and $(\mathrm{AR}+2 \mathrm{H})^{+\cdot}$ are loss of $\mathrm{H}$, ammonia, and $\mathrm{N}-\mathrm{C}_{\alpha}$ bond cleavage producing the $z$ ion at $m / z$ 159. Dissociations in the Arg side chain give fragments retaining the charged guanidine group, e.g., $m / z$ 60, 73, 87, and 100, which appear at the same $m / z$ in the ECID spectra of (GR + $2 \mathrm{H})^{2+}$ and $(\mathrm{AR}+2 \mathrm{H})^{2+}$ (Figure 2a). Another fragmentation in the $\mathrm{Arg}$ side chain of $(\mathrm{GR}+2 \mathrm{H})^{+\cdot}$ forms the fragment ion at $m / z$ 190, which shifts to $m / z 204$ for AR.

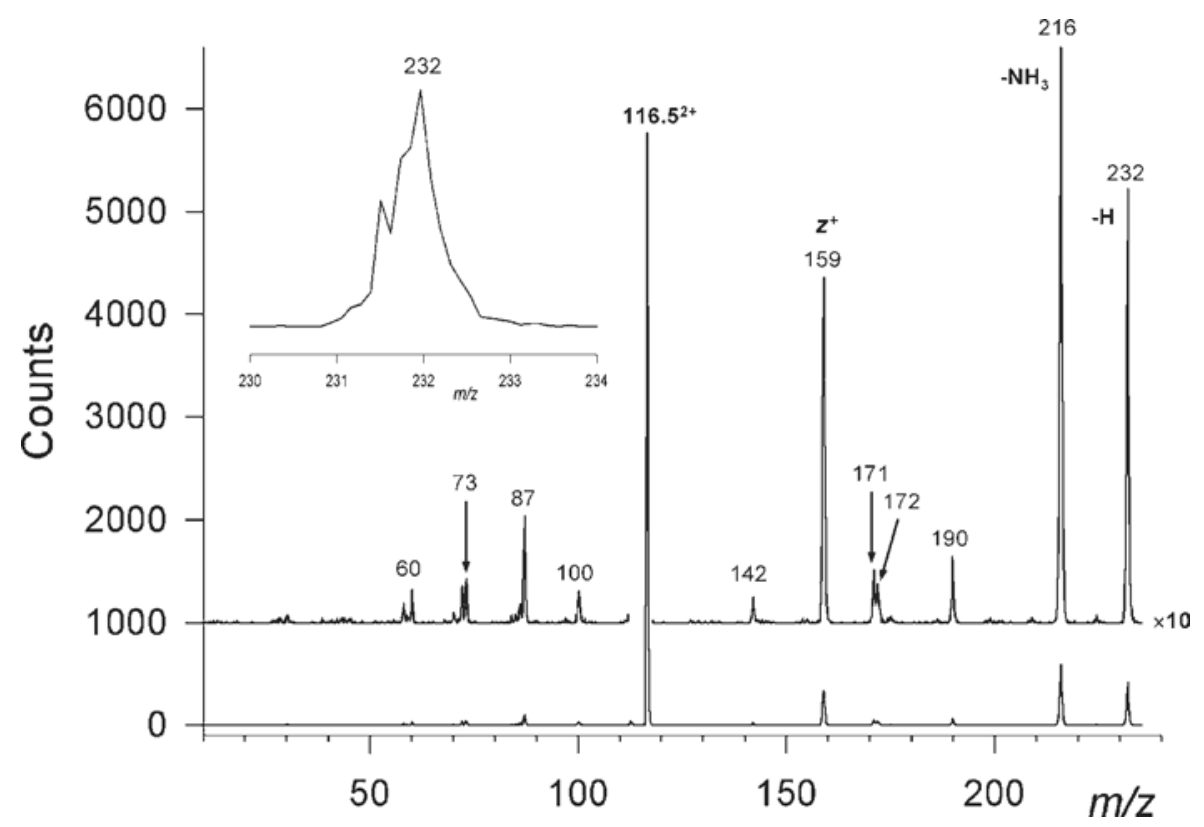

Figure 1. ECID/Cs spectrum of $(\mathrm{GR}+2 \mathrm{H})^{2+}$ at $100 \mathrm{keV}$. Inset shows the $\mathrm{m} / \mathrm{z} 230-234$ region where a charge-reduced $(\mathrm{GR}+2 \mathrm{H})^{+\cdot}$ ion would be expected at $\mathrm{m} / \mathrm{z} 233$. 

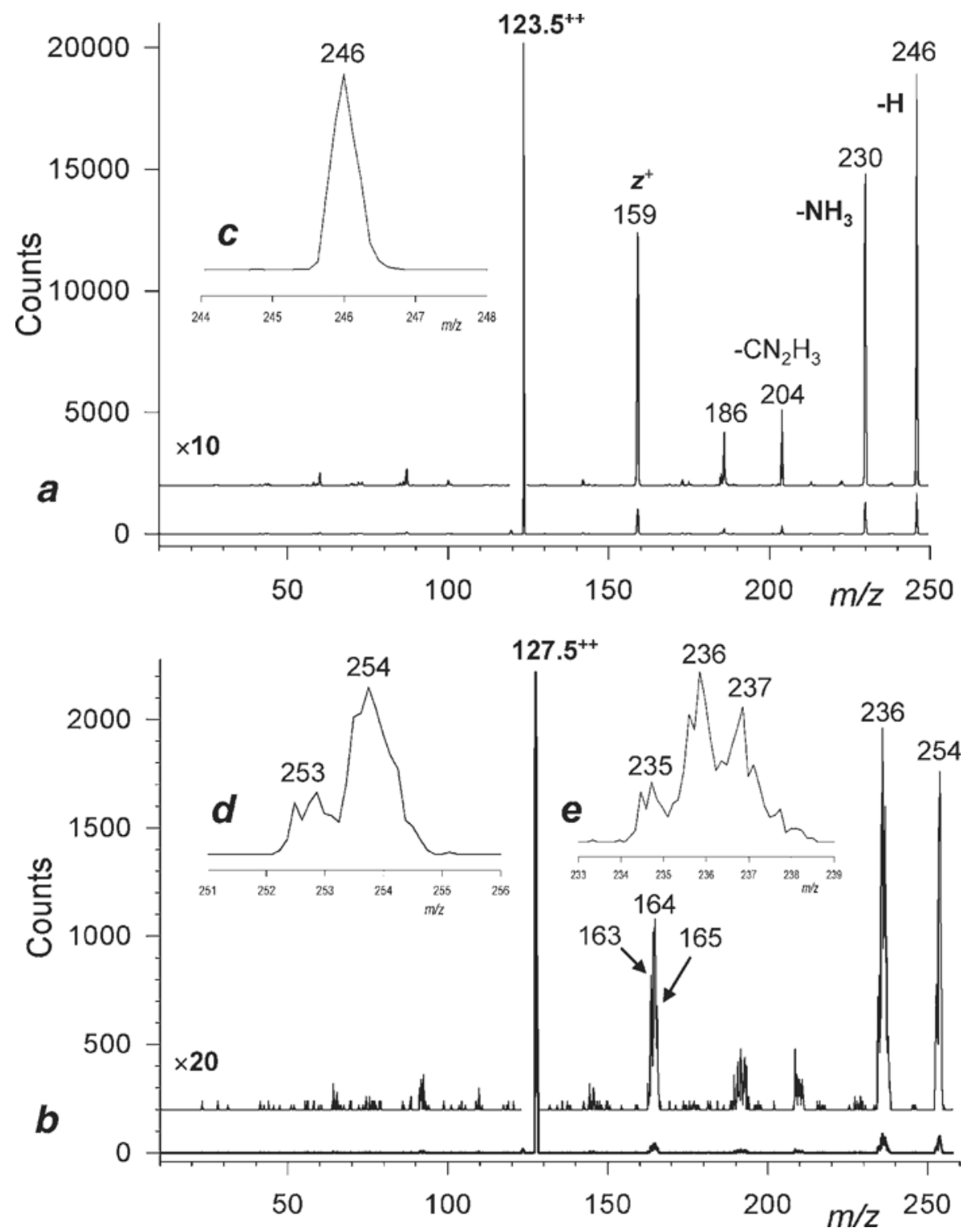

Figure 2. $\quad$ ECID/Cs spectra of $(\mathbf{a})(\mathrm{AR}+2 \mathrm{H})^{2+}(\mathrm{m} / \mathrm{z} 123.5)$ and $(\mathbf{b})\left(\mathrm{AR}-\mathrm{D}_{6}+2 \mathrm{D}\right)^{2+}(\mathrm{m} / \mathrm{z} 127.5)$ at 100 $\mathrm{keV}$. Inset (c) shows the expanded $m / z 244-248$ region from $(\mathrm{AR}+2 \mathrm{H})^{2+}$ measured at increased mass resolution. Inset (d) shows the expanded $\mathrm{m} / \mathrm{z}$ 251-256 region for loss of $\mathrm{H}$ and $\mathrm{D}$ from $\left(\mathrm{AR}-\mathrm{D}_{6}+2 \mathrm{D}\right)^{2+}$. Inset (e) shows the expanded $\mathrm{m} / \mathrm{z}$ 233-239 region for loss of ammonia from $\left(\mathrm{AR}-\mathrm{D}_{6}+2 \mathrm{D}\right)^{2+}$.

The neutral fragment was identified as a $\mathrm{CN}_{2} \mathrm{H}_{3}$ radical. This followed from the ECID spectra of $\left(\mathrm{AR}-\mathrm{D}_{6}+\right.$ $2 \mathrm{D})^{2+}(m / z 127.5$, Figure $2 \mathrm{~b})$ and $\left(\mathrm{AR}-\mathrm{D}_{5}+2 \mathrm{D}\right)^{2+}(\mathrm{m} / \mathrm{z}$ 127, not shown), which showed losses of $\mathrm{CN}_{2} \mathrm{D}_{3}$ and $\mathrm{CN}_{2} \mathrm{D}_{2}$. A loss of other neutral molecules nominally isobaric with $\mathrm{CN}_{2} \mathrm{H}_{3}\left(\mathrm{HCNO}, \mathrm{C}_{3} \mathrm{H}_{7}\right)$ would have resulted in the retention of seven to eight deuterium atoms in the fragment ion from $\left(A R-D_{6}+2 D\right)^{2+}$, contrary to the experiment.

To check for the presence of nondissociating chargereduced ions, we obtained an ECID spectrum of (AR + $2 \mathrm{H})^{2+}$ at increased mass resolution. This showed the $(\mathrm{AR}+2 \mathrm{H})^{+\cdot}$ signal at $<0.1 \%$ of that for $m / z 246$ (Figure $2 \mathrm{c}$ ), confirming the absence of surviving charge-reduced species.
The loss of $\mathrm{H}$ or $\mathrm{D}$ from $\left(\mathrm{AR}-\mathrm{D}_{6}+2 \mathrm{D}\right)^{2+}$ shows substantial kinetic isotope effects. Figure $2 \mathrm{~d}$ shows a 3.3:1 ratio for loss of $H$ and $D$, in contrast to the statistical ratio of $1: 4$ for loss of the ammonium or guanidinium $\mathrm{H}$ and $\mathrm{D}$ from the $\mathrm{D}_{8}$ ion. The loss of ammonia isotopologues from $\left(\mathrm{AR}-\mathrm{D}_{6}+2 \mathrm{D}\right)^{+\cdot}$ gives $\left[\mathrm{ND}_{3}\right]:\left[\mathrm{ND}_{2} \mathrm{H}\right]:\left[\mathrm{NDH}_{2}\right]$ in a 1:3:2 ratio (Figure $2 \mathrm{e}$ ), which differs from that for a random distribution of eight exchangeable deuterium atoms in the ion (7:7:1). This indicates that the incomplete exchange of eight of ten exchangeable protons in $(\mathrm{AR}+2 \mathrm{H})^{2+}$ mainly affects the Gly ammonium group, which is presumed to be lost preferentially upon ECID [25-27]. The D label distribution in the $\mathrm{z}$ ions from $\left(\mathrm{AR}-\mathrm{D}_{6}+2 \mathrm{D}\right)^{2+}$ shows a $4: 8: 3$ 
distribution of $D_{4}: D_{5}: D_{6}$ species to be compared with a statistical ratio of 5:8:2. This and the label distribution for the loss of ammonia indicate that a larger portion of the nonexchanged protons are in the Gly part of the ion.

We also studied the CID spectra of $(\mathrm{GR}+\mathrm{H})^{+}$and $(\mathrm{AR}+$ $\mathrm{H})^{+}$to elucidate dissociations of these ions when formed as intermediates by the facile loss of $\mathrm{H}$ from the corresponding charge-reduced precursors. CID of $(\mathrm{GR}+\mathrm{H})^{+}$ showed several fragment ions, e.g., $m / z 215$ (loss of $\mathrm{NH}_{3}$ ), 202 (loss of $\mathrm{CH}_{2} \mathrm{NH}_{2}$ ), and 187 (loss of $\mathrm{COOH}$ ), 159, 101, 87, 73, 70, 59, 43, and 30 (Figure S1, Supplementary Material, which can be found in the electronic version of this article). The $m / z 215,202$, and 187 peaks are unique for the CID spectrum of $(\mathrm{GR}+\mathrm{H})^{+}$but appear as very weak peaks in the ECID spectrum of $(\mathrm{GR}+2 \mathrm{H})^{2+}$ (Figure 1). Thus, we deduce that most fragments in the ECID spectrum are produced by dissociations of charge-reduced $(\mathrm{GR}+2 \mathrm{H})^{+\cdot}$ and not by consecutive dissociations of
$(\mathrm{GR}+\mathrm{H})^{+}$. Analysis of the CID spectrum of $(\mathrm{AR}+\mathrm{H})^{+}$ $(\mathrm{m} / \mathrm{z} 44$ and 201, Figure S2, Supplementary Material) led to similar conclusions.

$$
\begin{aligned}
& { }^{+} \mathrm{CR}^{-} \text {Mass Spectra of }(\mathrm{GR}+H)^{+} \text {and } \\
& (\mathrm{AR}+\mathrm{H})^{+}
\end{aligned}
$$

Charge inversion in both $(\mathrm{GR}+\mathrm{H})^{+}$and $(\mathrm{AR}+\mathrm{H})^{+}$ resulted in major fractions of the corresponding nondissociating anions at $m / z 232$ and 246, respectively (Figure $3 a$ and $b$ ). The fragment ions were assigned on the basis of mass shifts or their absence for GR and AR. The major dissociation product from both GR and AR is the $z$ anion at $m / z$ 158. This fragment ion further undergoes elimination of a 42-Da neutral fragment from the Arg side chain, possibly $\mathrm{HN}=\mathrm{C}=\mathrm{NH}$, to give the $m / z 116$ ion. Minor fragments are observed, e.g.,

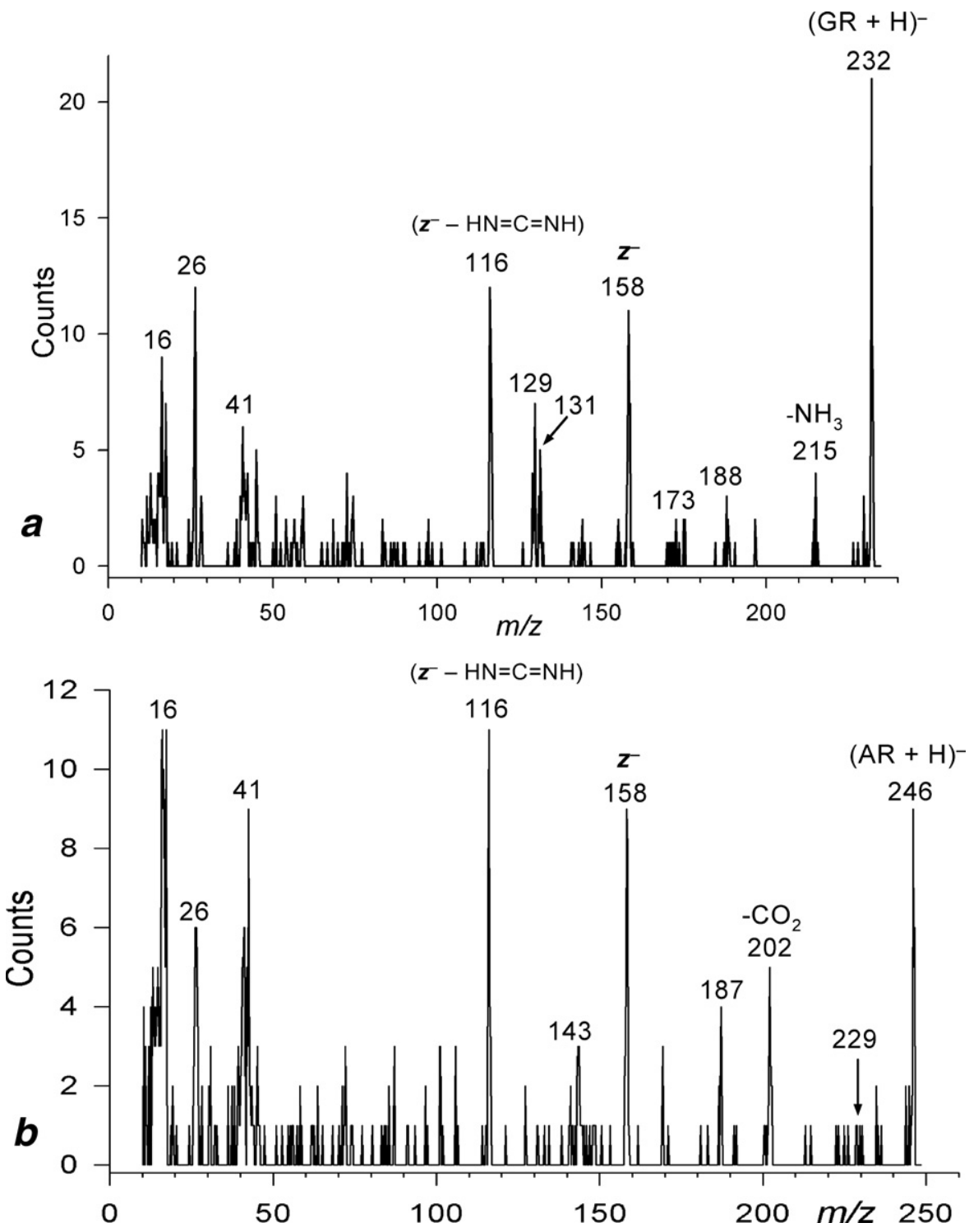

Figure 3. ${ }^{+} \mathrm{CR}^{-}$mass spectra of $(\mathbf{a})(\mathrm{GR}+\mathrm{H})^{+}$and $(\mathbf{b})(\mathrm{AR}+2 \mathrm{H})^{+}$, collisions with $\mathrm{Cs}$ at $50 \mathrm{keV}$. 

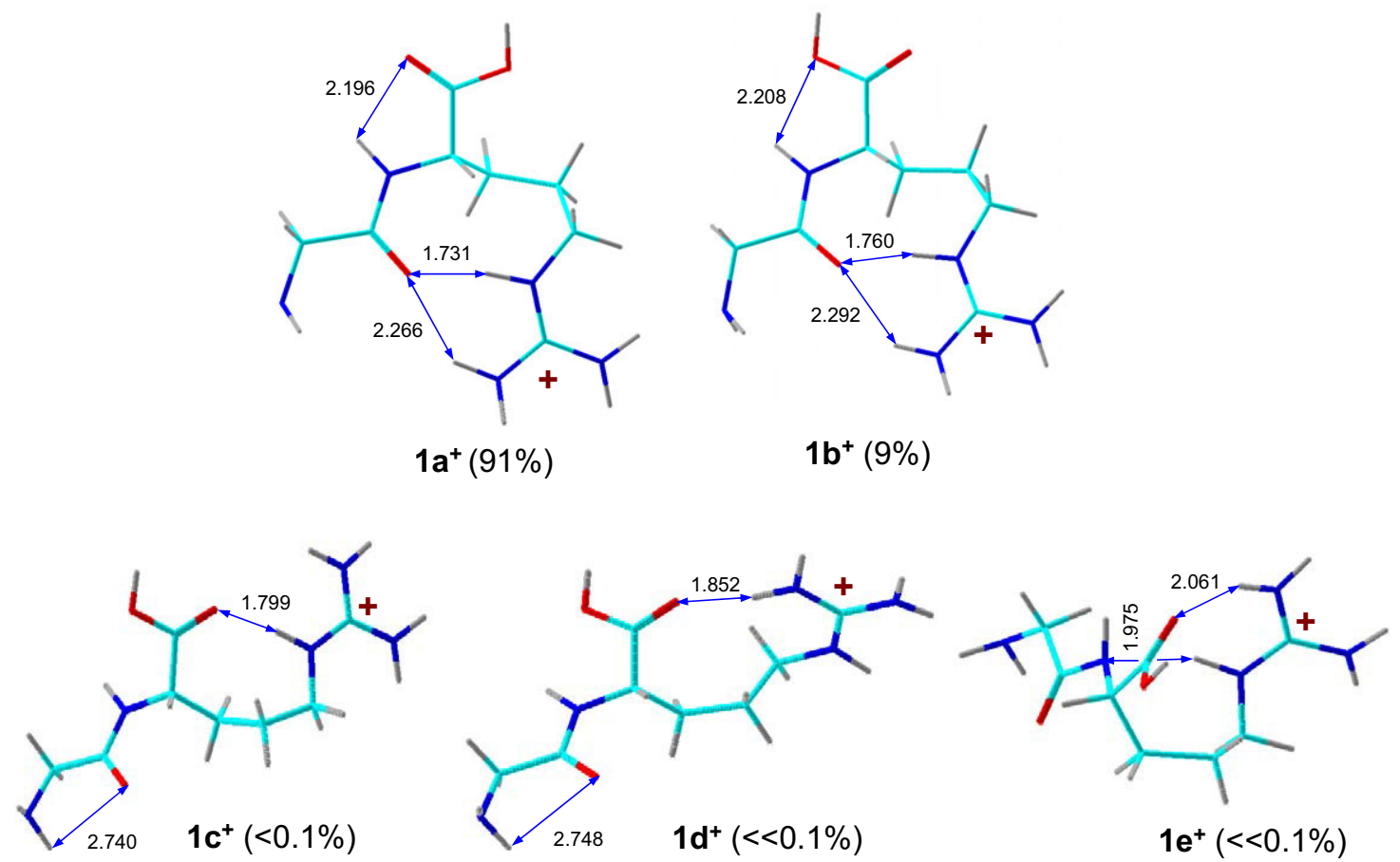

Figure 4. B3LYP/6-31+G(d,p) optimized structures of $(\mathrm{GR}+\mathrm{H})^{+}$cations. The atoms are colorcoded as follows: turquoise, $\mathrm{C}$; blue, $\mathrm{N}$; red, $\mathrm{O}$; gray, $\mathrm{H}$. Hydrogen bonds are indicated by blue double arrows and distances are given in Ångstrøms. The values in parentheses are the calculated equilibrium populations at $298 \mathrm{~K}$ in the gas phase.

$\mathrm{m} / \mathrm{z} 215,188,173$, and 129 from $(\mathrm{GR}+\mathrm{H})^{-}$and 229,202 , 187 , and 143 from $(\mathrm{AR}+\mathrm{H})^{-}$, which are attributed to eliminations of ammonia, $\mathrm{CO}_{2}$, and guanidine from the radical intermediates or survivor $(\mathrm{GR}+\mathrm{H})^{-}$and $(\mathrm{AR}+$ $\mathrm{H})^{-}$anions. It should be noted that negative ion spectra are highly selective in displaying only species that have finite and nonnegligible electron affinities to provide bound states for the charging electron. This holds for $z$ fragments, which are presumed to be $C_{\alpha}$ radicals that are known to form stable negative ions upon electron transfer $[28,29]$. However, the presence of nondissociating $(\mathrm{GR}+\mathrm{H})^{-}$and $(\mathrm{AR}+\mathrm{H})^{-}$anions indicates structures other than those for their precursor cations. The possible structures of $(\mathrm{GR}+\mathrm{H})^{+}$precursor ions, $(\mathrm{GR}+\mathrm{H})$ radicals, and dissociation products are addressed by electron structure theory computations described in the following section.

\section{Precursor Ion Structures}

Protonation in gas-phase GR and AR can be expected to preferentially occur in the arginine side chain, which has a substantially higher basicity than the $\mathrm{N}$-terminal amino group [30]. The conformations of singly protonated ions were studied for $(\mathrm{GR}+\mathrm{H})^{+}$and the fully optimized geometries of five low-energy conformers are shown in Figure 4. The structures show major hydrogen bonding interactions between the protonated guanidinium group and the carbonyl oxygen atoms [6]. $\mathrm{H}$-bonding in the neutral glycine residue is much weaker, as evidenced by the longer $\mathrm{N}-\mathrm{H} \cdots \mathrm{O}$ distances (Figure 4). Ion conformers in which the guanidinium moiety is H-bonded to the Gly amide carbonyl represent the most stable group, e.g., $\mathbf{1 a}^{+}$and $\mathbf{1} \mathbf{b}^{+}$, which differ in the orientation of the $\mathrm{COOH}$ group. Ion conformers in which the guanidinium group is $\mathrm{H}$-bonded to the carboxyl group, e.g., $\mathbf{1 c}^{+}$and $\mathbf{1 \mathbf { d } ^ { + }}$, are less stable than $\mathbf{1 a}^{+}$and $\mathbf{1} \mathbf{b}^{+}$(Table 1). Another ion conformer $\left(1 \mathrm{e}^{+}\right)$, in which the guanidinium is $\mathrm{H}$-bonded to both

Table 1. Relative energies of $(\mathrm{GR}+\mathrm{H})^{+}$cations and $(\mathrm{GR}+$ $2 \mathrm{H})^{2+}$ and $(\mathrm{AR}+2 \mathrm{H})^{2+}$ dications

\begin{tabular}{|c|c|c|}
\hline \multirow[b]{2}{*}{ Ion } & \multicolumn{2}{|c|}{ Relative energy ${ }^{a, b}$} \\
\hline & $\begin{array}{c}\text { B3LYP } \\
6-31+G(d, p)\end{array}$ & $\begin{array}{c}\text { B3-MP2 } \\
6-311++G(2 d, p)\end{array}$ \\
\hline $1 a^{+}$ & 0 & $0(0)^{\mathrm{c}}$ \\
\hline $1 b^{+}$ & 5 & $5(6)$ \\
\hline $1 c^{+}$ & 29 & $32(26)$ \\
\hline $1 d^{+}$ & 31 & $35(31)$ \\
\hline $1 e^{+}$ & 40 & $37(44)$ \\
\hline $2 a^{2+}$ & 0 & $0(0)^{\mathrm{c}}$ \\
\hline $2 b^{2+}$ & -2 & $-3(3)$ \\
\hline $2 c^{2+}$ & -1 & $-2(0.8)$ \\
\hline $3 a^{2+}$ & 0 & $0(0)^{\mathrm{c}}$ \\
\hline $3 b^{2+}$ & -2 & $-3(0.6)$ \\
\hline $3 c^{2+}$ & -0.5 & $-1(1)$ \\
\hline
\end{tabular}

an units of $\mathrm{kJ} \mathrm{mol}^{-1}$.

bIncluding B3LYP/6-31+G(d,p) zero-point corrections and $H_{298}$ enthalpies and referring to $298 \mathrm{~K}$.

${ }^{\text {CRelative }} 298 \mathrm{~K}$ free energies in parentheses. 
$\mathrm{COOH}$ and the amide group, is calculated to be slightly less stable than $\mathbf{1} \mathbf{c}^{+}$and $\mathbf{1} \mathbf{d}^{+}$. The calculated free energies indicate $\mathbf{1 a}^{+}$to be the most populated gas-phase conformer of the $(\mathrm{GR}+\mathrm{H})^{+}$cations $(91 \%$ at $298 \mathrm{~K})$. Similar ordering of conformer stabilities is expected for $(\mathrm{AR}+\mathrm{H})^{+}$cations because the dominant ion-dipole and dipole-dipole interactions in the ion are not much affected by the Ala methyl group.

The relative enthalpies of doubly protonated GR and AR are influenced by attractive ion-dipole and dipoledipole interactions and repulsive Coulomb interactions between the charged groups. A balance of these two interactions substantially reduces the number of lowenergy conformers for dipeptides. The calculated free energies indicate three major conformers to be present at gas-phase equilibrium (Figure 5). Dications $\mathbf{2} \mathbf{b}^{\mathbf{2 +}}$ and $3 \mathbf{b}^{2+}$, which have the protonated arginine side chains $\mathrm{H}$-bonded to the $\mathrm{COOH}$ carbonyls, are marginally more stable thermochemically than the respective unfolded conformers $2 \mathbf{a}^{2+}$ and $3 \mathbf{a}^{2+}$ (Table 1 ). H-bonding by the guanidinium imine proton, as in $2 c^{2+}$ and $3 c^{2+}$, is slightly less favorable. The H-bonding decreases the entropy of $\mathbf{2} b^{2+}$ and $2 c^{2+}$ relative to that of the unfolded conformer $2 \mathrm{a}^{2+}$ and thus compensates for the enthalpy difference. The AR dications $3 \mathbf{a}^{2+}-3 \mathbf{c}^{2+}$ show a similar trend. The calculated free energies indicate that all three most stable conformers of $(\mathrm{GR}+2 \mathrm{H})^{2+}$ and $(\mathrm{AR}+2 \mathrm{H})^{2+}$ can coexist at equilibrium in the gas phase and will undergo charge reduction by electron transfer from Cs.

\section{Electron Transfer to $(\mathrm{GR}+\mathrm{H})^{+}$and Dissociation Energetics of $(G R+H)$}

Fast ions $\mathbf{1}$ and $\mathbf{2}$ undergo vertical electron transfer upon collision with Cs atoms. The timescale for the collision can be estimated from the path length for the interaction that is approximated as a sum of the atomic and molecular diameters, 4.88 and $9 \AA$ for Cs and $\mathbf{1 a}^{+}$, respectively, and the ion velocity $\left(2 \times 10^{5} \mathrm{~ms}^{-1}\right.$ at 50 $\mathrm{keV})$. This gives the interaction time as $7 \mathrm{fs}$, which is shorter than the vibrational period of the fastest vibration in $\mathbf{1 a}^{+}$. The vertical recombination energy of $\mathbf{1 a}^{+}$ $\left(R E_{\mathrm{v}}=2.64 \mathrm{eV}\right.$, Table 2$)$ is substantially lower than its adiabatic recombination energy $(3.44 \mathrm{eV})$, which is equal to the adiabatic ionization energy of radical 1a. Significantly, the $R E_{\mathrm{v}}$ of all $(\mathrm{GR}+\mathrm{H})^{+}$ion conformers are lower than the ionization energy of $\mathrm{Cs}(3.894 \mathrm{eV})$, indicating that the collisional electron transfer is endoergic. Under such conditions, the mean internal energy
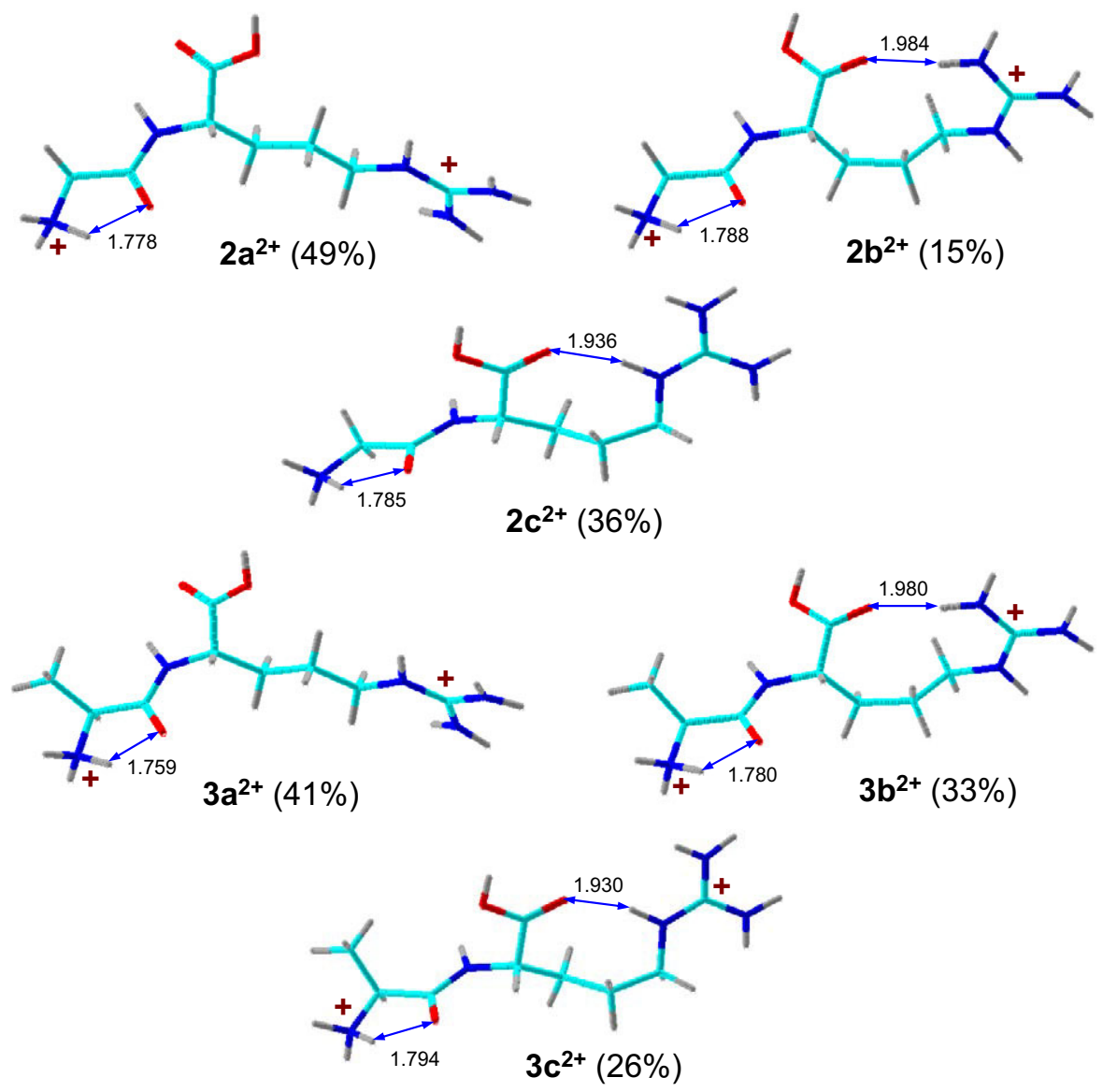

Figure 5. B3LYP/6-31+G(d,p) optimized structures of $(\mathrm{GR}+2 \mathrm{H})^{2+}$ and $(\mathrm{AR}+2 \mathrm{H})^{2+}$ dications. The atoms are color-coded as in Figure 4 . The values in parentheses are the calculated equilibrium populations at $298 \mathrm{~K}$ in the gas phase for each group of conformers. 
Table 2. Ion recombination energies

\begin{tabular}{ccc} 
& \multicolumn{2}{c}{$\begin{array}{c}\text { Recombination } \\
\text { energy }\end{array}$} \\
\cline { 2 - 3 } Ion & $\mathrm{REa}^{\mathrm{b}}$ & $\mathrm{REv}^{\mathrm{c}}$ \\
\hline \hline $\mathbf{1 a}^{+}$ & 3.44 & 2.64 \\
$\mathbf{1 b}^{+}$ & 3.42 & \\
$\mathbf{1}^{+}$ & 3.75 & 2.81 \\
$\mathbf{1 d}^{+}$ & 3.69 & 2.75 \\
$\mathbf{2 a}^{\mathbf{2 +}}$ & $5.79^{\mathbf{d}}$ & 4.96 \\
& $5.51^{\mathrm{e}}$ & \\
$\mathbf{2 b}^{\mathbf{2 +}}$ & 5.62 & 5.31 \\
$\mathbf{2}^{\mathbf{2 +}}$ & $6.59^{\text {f }}$ & 5.29 \\
$\mathbf{3 a}^{\mathbf{2 +}}$ & - & 5.03 \\
$\mathbf{3 b}^{\mathbf{2 +}}$ & - & 5.07 \\
$\mathbf{3 c}^{\mathbf{2 +}}$ & - & 5.04 \\
\hline
\end{tabular}

${ }^{a}$ Absolute values in units of electron volts.

${ }^{b}$ Adiabatic recombination energies from combined B3LYP and PMP2/ $6-311++G(2 d, p)$ single-point energy calculations and including B3LYP/ $6-31++G(d, p)$ zero-point energy corrections.

'Vertical recombination energies from combined B3LYP and PMP2/6$311++G(2 d, p)$ single-point energy calculations.

'Forming $2 \mathbf{a a}^{+}$.

eforming $2 \mathbf{a b}^{+\cdot}$.

${ }^{f}$ Spontaneously isomerized to Gly-enolimine isomer $\mathbf{2} \mathbf{c a}^{+}$.

$\langle\mathrm{E}\rangle$ of the reduced species can be approximated by a sum of the precursor ion rovibrational $\left(H_{\text {rovib }}=38 \mathrm{~kJ}\right.$ $\mathrm{mol}^{-1}$ at $\left.298 \mathrm{~K}\right)$ and the Franck-Condon energy $\left(E_{\mathrm{FC}}=\right.$ $70 \mathrm{~kJ} \mathrm{~mol}^{-1}$ ) (eq 1) [31]:

$$
\langle\mathrm{E}\rangle=\mathrm{H}_{\mathrm{rovib}}+\mathrm{E}_{\mathrm{FC}}=38+70=108 \mathrm{~kJ} \mathrm{~mol}^{-1}
$$

According to eq 1, radical 1a acquires on average $108 \mathrm{~kJ}$ $\mathrm{mol}^{-1}$ vibrational energy upon vertical reduction. The radical excitation through Frank-Condon effects is mainly attributable to the differences in the relaxed geometries of the guanidinium group in the cation and radical [7]. The guanidinium group in $\mathbf{1 a}^{+}$is near planar to allow $\pi$-electron interactions of the $\mathrm{C}$ and $\mathrm{N}$ atoms and has relatively short $\mathrm{C}-\mathrm{N}$ bonds at $1.326-1.349 \AA$. The guanidinium group in radical 1a is puckered at all $\mathrm{C}$ and $\mathrm{N}$ centers and has longer $\mathrm{C}-\mathrm{N}$ bonds at $1.419-$ $1.428 \AA$. Vertical electron attachment to $\mathbf{1 a}^{+}$is expected to result in excitation of the stretching $(1231,1311,1321$ $\left.\mathrm{cm}^{-1}\right)$ and out-of-plane deformation $(301,427,479,500$, 539,674 , and $\left.698 \mathrm{~cm}^{-1}\right)$ modes in the guanidine group.

In contrast to $(\mathrm{GR}+\mathrm{H})^{+}$cations, the pertinent radicals 1a-1d fall into a narrow range of relative energies that are within $8 \mathrm{~kJ} \mathrm{~mol}^{-1}$ (Table 4). The radical structures and relative energies $\left(\mathrm{kJ} \mathrm{mol}^{-1}\right)$ are shown in Scheme $\mathbf{1}$. In view of the substantial vibrational excitation in 1a and low barriers for Arg side-chain rotations (10-12 kJ $\mathrm{mol}^{-1}$ ) [6], radical conformers $\mathbf{1 a - 1 d}$ are expected to be at fast equilibrium in the gas phase. The diminished differences in radical relative energies are mainly a result of the weakening of intramolecular hydrogen bonds of the guanidine group, as illustrated by the $\mathrm{N}-\mathrm{H} \cdots \mathrm{O}=\mathrm{C}$ distances, which are 1.73 and $2.18 \AA$ in $\mathbf{1 a}^{+}$ and 1a, respectively. Weak $\mathrm{H}$-bonding also accounts for the spontaneous unfolding of the Arg side chain upon electron attachment to $1 \mathrm{c}^{+}$giving radical $\mathbf{1 c}$.
Loss of guanidine is one of the dissociations observed upon ${ }^{+} \mathrm{CR}^{-}$of $(\mathrm{GR}+\mathrm{H})^{+}$and $(\mathrm{AR}+\mathrm{H})^{+}$. Dissociation of the $\mathrm{C}-\mathrm{N}$ (guanidine) bond leading to loss of guanidine is mildly endothermic to form alkyl radical $4\left(\Delta H_{\mathrm{rxn}}=16 \mathrm{~kJ}\right.$ $\mathrm{mol}^{-1}$, Table 4) and has a loose transition state (TS1) at $E_{\mathrm{TS} 1}=54 \mathrm{~kJ} \mathrm{~mol}^{-1}$ above 1a (Scheme 2). Note that loss of guanidine can start from any of the radical conformers and proceed through multiple transition states differing in side-chain and backbone conformations [6]. The primary alkyl radical (4) formed by loss of guanidine from $\mathbf{1 a}$ is unlikely to have a sufficient electron affinity to form a stable anion upon electron transfer [6]. As reported previously for arginine radicals [6], radical fragments of the 4 type can exothermically rearrange by $\mathrm{C}_{\alpha}-\mathrm{H}$ atom migration to form stable $\mathrm{C}_{\alpha}$-radicals, e.g., 5 (Scheme 2), which has a substantial electron affinity $\left[E A_{\mathrm{v}}(5)=1.28 \mathrm{eV}\right]$. However, loss of guanidine and fragment rearrangement are consecutive reactions that must occur during the radical residence time in the collision cell ( $\leq 200 \mathrm{~ns}$ ), and thus the formation of dissociation products of the 5 type may be kinetically limited and affect detection of the corresponding anions.

The formation from 1a of a neutral $z$ fragment and a glycine enol imine was calculated to be $37 \mathrm{~kJ} \mathrm{~mol}^{-1}$ endothermic (Table 4). The dissociation can proceed by various mechanisms involving one or more transition states that were not studied here.

Neither radical 1a nor its conformers have bound states for an extra electron to form stable anions, as documented by negative vertical electron affinities for 1a and 1d (Table 3). The fact that nondissociating (GR + $\mathrm{H})^{-}$and $(\mathrm{AR}+\mathrm{H})^{-}$anions were detected in ${ }^{+} \mathrm{CR}^{-}$ spectra indicated that a rearrangement in $\mathbf{1 a}$ or its conformers took place to form radical structures that could give stable anions upon electron transfer [29]. In addition, the rearrangement must occur on the experimental timescale of $200 \mathrm{~ns}$. We investigated the migration of hydrogen atoms from the Arg and Gly $\mathrm{C}_{\alpha}$ positions onto the guanidine $C$ atom. Similar rearrangements have been reported to account for stabilization of arginine and arginine amide radicals $[6,9]$. Migration of the $\operatorname{Arg} \mathrm{C}_{\alpha}-\mathrm{H}$ atom is $30 \mathrm{~kJ} \mathrm{~mol}^{-1}$ exothermic to form radical 1f and requires $39 \mathrm{~kJ} \mathrm{~mol}^{-1}$ in TS2 (Table 4).

Table 3. Radical electron affinities

\begin{tabular}{ccc}
\hline & \multicolumn{2}{c}{ Electron affinity } \\
\cline { 2 - 3 } Radical & EAa $^{\mathrm{b}}$ & EAv $^{\mathrm{c}}$ \\
\hline $\mathbf{1 a}$ & - & -0.38 \\
$\mathbf{1 d}$ & - & -0.16 \\
$\mathbf{1 f}$ & 2.03 & 1.43 \\
$\mathbf{1 g}$ & 1.29 & 0.10 \\
$\mathbf{z}$ & 2.00 & 1.59 \\
$\mathbf{5}$ & 1.71 & 1.28 \\
\hline
\end{tabular}

a Absolute values in units of electron volts.

bAdiabatic electron affinities from combined B3LYP and PMP2/6$311++G(2 d, p)$ single-point energy calculations and including B3LYP/6$31++\mathrm{G}(\mathrm{d}, \mathrm{p})$ zero-point energy corrections.

cVertical electron affinities from combined B3LYP and PMP2/6-311++G(2d,p) single-point energy calculations. 


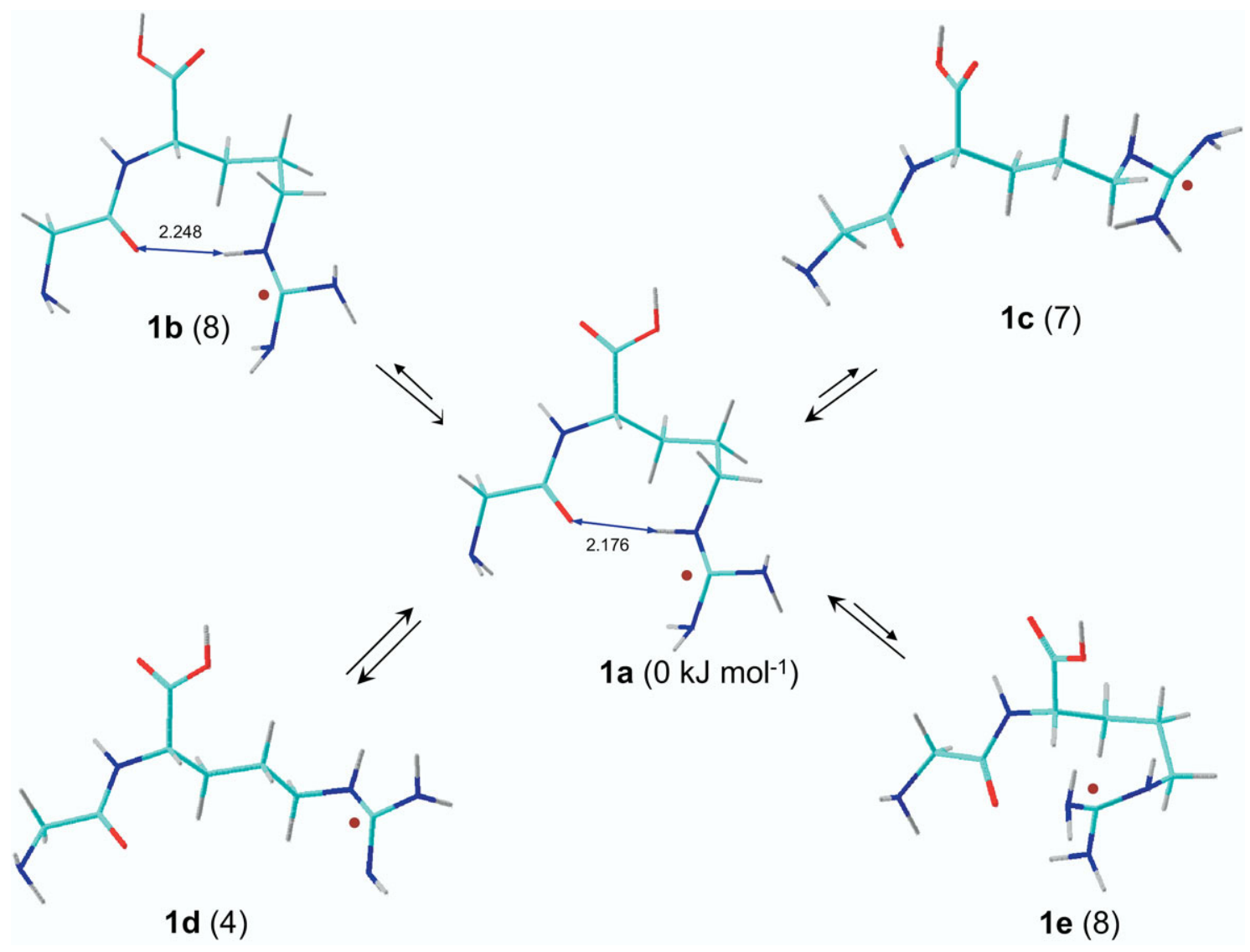

Scheme 1

Migration of the Gly $\mathrm{C}_{\alpha}-\mathrm{H}$ atom is $45 \mathrm{~kJ} \mathrm{~mol}^{-1}$ exothermic to form radical $1 \mathrm{~g}$ but requires a higher activation energy in TS3 $\left(E_{\mathrm{TS} 3}=62 \mathrm{~kJ} \mathrm{~mol}^{-1}\right)$. Thus, both rearrangements are thermodynamically favorable but their kinetics may differ. Radicals $\mathbf{1 f}$ and $\mathbf{1 g}$ have substantial adiabatic electron affinities (Table 3). How- ever, the vertical EA differ and, although that for $\mathbf{1 f}$ is substantial $(1.43 \mathrm{eV})$, that for $\mathbf{1 g}$ is only $0.10 \mathrm{eV}$ (Table 3). Thus, apparently the formation of $(\mathrm{GR}+\mathrm{H})^{-}$is more favorable from 1f. We note that $\mathbf{1 g}$ is likely to have a number of side-chain conformers of similar energy, but those were not studied here.

Table 4. Relative and dissociation energies of $(\mathrm{GR}+\mathrm{H})$ radicals

\begin{tabular}{|c|c|c|c|c|}
\hline \multirow[b]{3}{*}{ Species/reaction } & \multicolumn{4}{|c|}{ Relative energy ${ }^{a, b}$} \\
\hline & \multicolumn{2}{|c|}{$6-31++G(d, p)$} & \multicolumn{2}{|c|}{$6-311++G(2 d, p)$} \\
\hline & B3LYP & B3LYP & PMP2 & B3-PMP2 \\
\hline $1 a \rightarrow 1 b$ & 8 & 9 & 8 & 8 \\
\hline $1 a \rightarrow 1 c$ & 3 & 3 & 11 & 7 \\
\hline $1 a \rightarrow 1 d$ & 0.1 & -1 & 9 & 4 \\
\hline $1 \mathrm{a} \rightarrow 1 \mathrm{e}$ & 10 & 10 & 6 & 8 \\
\hline $1 \mathrm{a} \rightarrow \mathrm{TS} 1$ & 52 & 49 & 58 & $54(56)^{c}(54)^{d}$ \\
\hline $1 \mathrm{a} \rightarrow \mathrm{TS} 2$ & 39 & 43 & 35 & $39(39)^{c}(39)^{d}$ \\
\hline $1 a \rightarrow 1 f$ & -31 & -32 & -29 & $-30(-29)^{c}(-30)^{d}$ \\
\hline $1 \mathrm{a} \rightarrow 1 \mathrm{~g}$ & -45 & -46 & -44 & -45 \\
\hline $1 \mathrm{a} \rightarrow \mathrm{TS} 3$ & 67 & 69 & 55 & $62(62)^{c}(61)^{d}$ \\
\hline $\mathbf{1 a} \rightarrow \mathbf{4}+\mathrm{HN}=\mathrm{C}\left(\mathrm{NH}_{2}\right)_{2}$ & -6 & 0 & 32 & 16 \\
\hline $4 \rightarrow 5$ & -91 & -91 & -74 & -82 \\
\hline $1 \mathbf{a} \rightarrow \boldsymbol{z}+\mathrm{H}_{2} \mathrm{NCH}_{2} \mathrm{C}(\mathrm{OH})=\mathrm{NH}$ & 26 & 19 & 55 & 37 \\
\hline
\end{tabular}

an units of $\mathrm{kJ} \mathrm{mol}^{-1}$.

bIncluding $\mathrm{B} 3 \mathrm{LYP} / 6-31++\mathrm{G}(\mathrm{d}, \mathrm{p})$ zero-point energies and referring to $0 \mathrm{~K}$.

${ }^{\mathrm{B}} \mathrm{B} 3-\mathrm{PMP} 2 / 6-311++\mathrm{G}(3 \mathrm{df}, 2 \mathrm{p})$ energies.

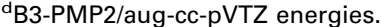




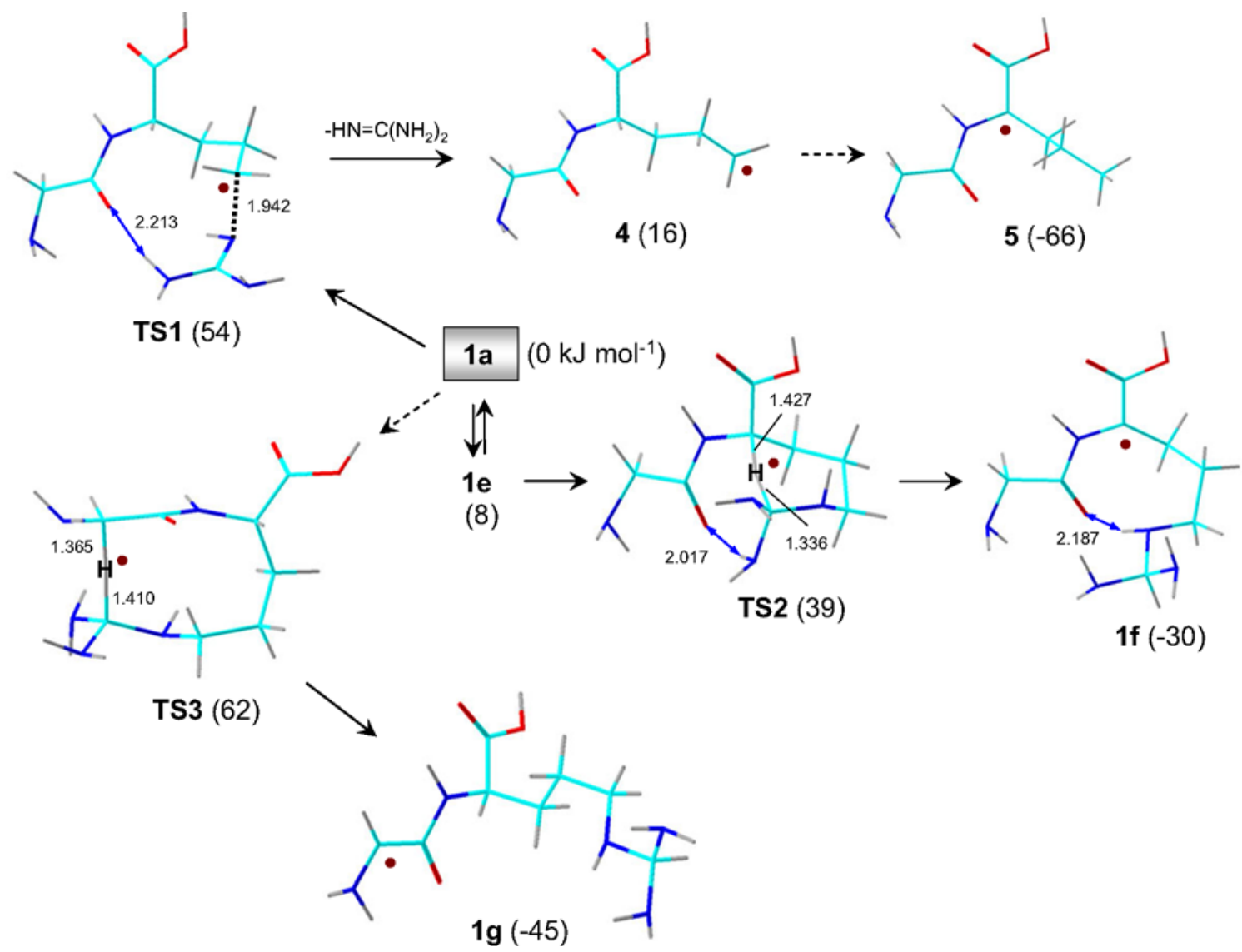

Scheme 2

To form stable $\mathrm{C}_{\alpha}$-radical intermediates, the $\mathrm{C}_{\alpha}-\mathrm{H}$ atom migrations must occur on the experimental timescale for radical lifetimes between the neutralizing and ionizing collisions ( $t \leq 200 \mathrm{~ns})$. We used RRKM calculations to obtain the unimolecular rate constants $\left(k, \mathrm{~s}^{-1}\right)$ for $\mathrm{C}_{\alpha}-\mathrm{H}$ migrations in $(\mathrm{GR}+\mathrm{H})^{\prime}$ radicals and competing isomerizations and dissociations. Because of the fast side-chain rotation in arginine radicals $\left(k \geq 10^{11} \mathrm{~s}^{-1}\right.$ [6]), the radical conformers are presumed to rapidly equilibrate. Thus, according to the Curtin-Hammett principle [32] the relevant reactant structure is that of the most stable conformer 1a. The calculated rate constants $\left(\log k, \mathrm{~s}^{-1}\right)$ are shown in Figure 6a. Arginine $\mathrm{C}_{\alpha}-\mathrm{H}$ atom migration has the lowest TS energy and dominates at low excitations in the reactant $\left(k_{2}\right.$, Figure $6 a)$. However, the loss the guanidine has a looser TS and becomes faster at $E \geq 90 \mathrm{~kJ} \mathrm{~mol}^{-1}\left(k_{1}\right.$, Figure 6a). The fraction of $1 \mathrm{f}$ formed from 1a can be expressed as

$$
\frac{\mathbf{1 f}}{\mathbf{1 a}}=\frac{k_{2}}{k_{1}+k_{2}-\sum k_{d i s}}\left[e^{-\Sigma k_{d i s} t}-e^{-\left(k_{1}+k_{2}\right) t}\right]
$$

where $\sum k_{\text {dis }}$ are the combined rate constants for reactions depleting $\mathbf{1 f}$, and $k_{1}$ and $k_{2}$ are as in Figure 6a. Assuming $\sum k_{\mathrm{dis}} \ll\left(k_{1}+k_{2}\right)$, and $t=200 \mathrm{~ns}$ for the reaction timescale, we calculated the percentage of $\mathbf{1 a}$ rearranging to $\mathbf{1 f}$ as a function of the radical internal energy (Figure 6b). The conversion has a maximum of $12 \%$ for 1a having $115 \mathrm{~kJ} \mathrm{~mol}^{-1}$ internal energy (Figure $6 b)$. For $(\mathrm{GR}+\mathrm{H})^{-}$acquiring the mean internal energy upon electron transfer $\left(\langle E\rangle=108 \mathrm{~kJ} \mathrm{~mol}^{-1}\right.$; see preceding text), the dissociation kinetics predicts $11 \%$ conversion to 1f. RRKM calculations were also performed with TS energies calculated by B3-PMP2/6-311++G(3df,2p) and B3-PMP2/aug-cc-pVTZ and gave similar fractions of $\mathbf{1 f}$ (11 and $12 \%$, respectively). The relevant rate constants and conversions are shown in Figure S3 (Supplementary Material). Note that the $\mathrm{C}_{\alpha}$-radical $\mathbf{1 f}$ is more stable than 1a and thus the reverse $\mathrm{H}$-atom migration, $\mathbf{1 f} \rightarrow \mathbf{T S} \mathbf{2} \rightarrow \mathbf{1 a}$, has a greater activation energy and is substantially slower $\left(k_{3}\right.$, Figure $\left.6 \mathrm{a}\right)$ than the forward migration. Likewise, migration of the Gly $\mathrm{C}_{\alpha}-\mathrm{H}$ to form the Gly $\mathrm{C}_{\alpha}$ radical $\mathbf{1 g}$ or its side-chain conformers has a relatively high activation energy $\left(62 \mathrm{~kJ} \mathrm{~mol}^{-1}\right)$ and tight transition state (TS3) and is not expected to occur competitively $\left(k_{4}\right.$, Figure 6a). Thus, although $1 \mathrm{~g}$ is thermodynamically more stable than $\mathbf{1 f}$, its formation from $\mathbf{1 a}$ is disfavored kinetically. Another possible pathway to forming $1 \mathrm{~g}$ would be by $\mathrm{H}$-atom migrations between the Gly and $\operatorname{Arg} \mathrm{C}_{\alpha}$-positions, e.g., $\mathbf{1 f} \rightarrow \mathbf{1 g}$, as studied for other peptide radicals [33,34]. We did not study such migrations, although it should be noted that their kinetics would be limited by the formation of an initial $\mathrm{C}_{\alpha}$-radical, e.g., $\mathbf{1 f}$, which depends on $k_{2}$. 

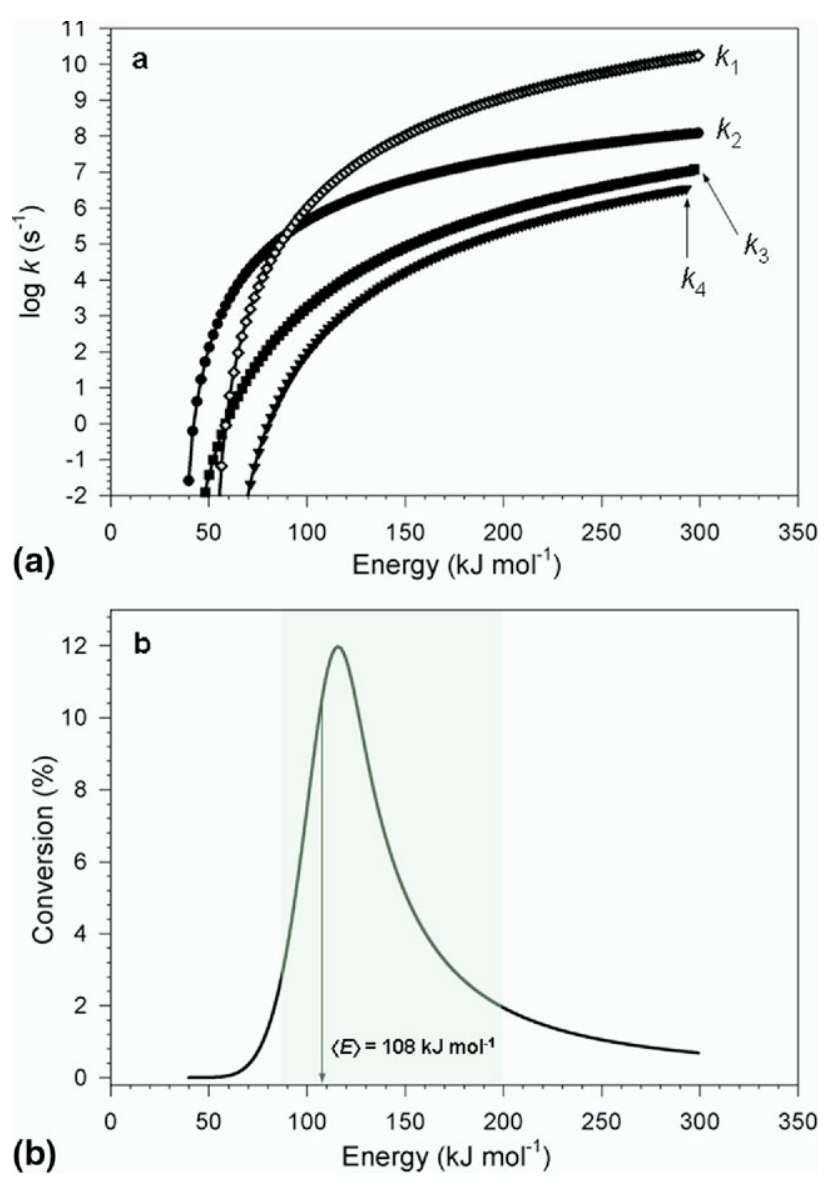

Figure 6. (a) Calculated RRKM unimolecular rate constants (log $k, \mathrm{~s}^{-1}$ ) for dissociations and isomerizations of $1 \mathrm{a}$. $k_{1}$ (open diamonds): $\mathrm{C}-\mathrm{N}$ (guanidine) bond dissociation through TS1; $k_{2}$ (full circles): $\mathrm{Arg}_{\alpha}-\mathrm{H}$ atom migration through TS2; $k_{3}$ (full squares) inverse $\mathrm{H}$ atom migration in $\mathbf{1 f}$ through TS2; $k_{4}$ (full triangles): Gly $\mathrm{C}_{\alpha}-\mathrm{H}$ atom migration through TS3. (b) Calculated fractions of $1 \mathrm{a}$ converted to 1 f on a 200-ns timescale. The arrow indicates the mean internal energy in 1a, the green shaded region indicates the approximate range of internal energies in $\mathbf{1 a}$.

\section{Electron Transfer to $(\mathrm{GR}+2 \mathrm{H})^{2 \pm}$ and Dissociation Energetics of $(\mathrm{GR}+2 \mathrm{H})^{+}$.}

The doubly charged $(\mathrm{GR}+2 \mathrm{H})^{2+}$ precursor ions were calculated to consist of a mixture of three major conformers- $2 \mathbf{a}^{2+}, \mathbf{2} \mathbf{b}^{2+}$, and $2 \mathbf{c}^{2+}$ (Figure 5) - that upon electron transfer give the corresponding cation radical conformers $2 \mathbf{a}^{+\cdot}, \mathbf{2} \mathbf{b}^{+\cdot}$, and $2 \mathbf{c}^{+\cdot}$. In addition, either of the charge-carrying group may be reduced in the dications to give rise to further conformational isomers. For example, charge reduction in $\mathbf{2 \mathbf { a } ^ { 2 + }}$ was calculated to produce two cation radicals that were found to be local energy minima. The more stable one $\left(2 \mathrm{aa}^{+*}\right.$, Scheme 3) has a pyramidized guanidine group that carries $98 \%$ of the unpaired electron density and has all the characteristics of a guanidinium radical. The Gly moiety carries $72 \%$ of positive charge and the $\mathrm{N}$-terminal $\mathrm{NH}_{3}$ groups shows a typical ionic $\mathrm{H}-$ bonding distance to the amide carbonyl (1.654 $\AA$ ). The other structure $\left(2 \mathbf{a b}^{+\cdot}\right.$, Scheme 3 ) is $27 \mathrm{~kJ} \mathrm{~mol}^{-1}$ less stable than $2 \mathbf{a a}^{+\cdot}$ and can be represented as a Gly ammonium radical with a weak H-bonding to the Gly amide and having a near-planar guanidinium group in the Arg residue. However, the calculated spin densities in $2 \mathbf{a b}^{+\cdot}$ place $61 \%$ of the unpaired electron density in the Gly residue and $37 \%$ in the Arg guanidine group. Since $2 \mathbf{a a}^{+\cdot}$ and $2 \mathbf{a b}^{+\cdot}$ differ in the electron distribution, they can be considered two different electronic states of the same species, each existing in a different potential energy well. It should be noted that the relative energies of $2 \mathbf{a a}^{+\cdot}$ and $2 \mathbf{a b}^{+\cdot}$ depend on the computational method used. MP2 calculations placed $2 \mathbf{a a}^{+\cdot}$ below $2 \mathbf{a b}^{+\cdot}$, whereas B3LYP gave similar energies for both (Table 5). The delocalization of spin and charge in $2 \mathbf{a b}^{+\cdot}$ suggests that the captured electron cannot be assigned to reduce just one charged group in the peptide dication [10]. Relevant to ECID, vertical electron transfer to $2 \mathbf{a}^{2+}$ produces a state that initially has the ion geometry. The charge and spin distribution in vertically formed $2 \mathrm{a}^{+\cdot}$ shows $67 \%$ of unpaired electron density in the Gly moiety, $22 \%$ in the $\mathrm{COOH}$ group, and $8 \%$ in the Arg guanidine moiety. This spin delocalization is further illustrated by the molecular orbitals for the ground and excited electronic states in vertically reduced $2 \mathbf{a}^{+\cdot}$ (Figure 7). This shows the ground state (SOMO) as a superposition of the ammonium 3s Rydberg-like orbital, and the Gly amide, Arg- $\mathrm{COOH}$, and guanidinium $\pi^{*}$ orbitals. The excited states are closely spaced with the $\mathrm{C}$ and $\mathrm{D}$ states consisting of superpositions of amide and carboxyl $\pi^{*}$ orbitals $[35,36]$.

The recombination energies for $2 \mathrm{a}^{2+}$ were calculated as $\mathrm{RE}_{\mathrm{v}}=4.96 \mathrm{eV}$ and $\mathrm{RE}_{\mathrm{a}}=5.79$ and $5.51 \mathrm{eV}$, forming $2 \mathbf{a a}^{+\cdot}$ and $2 \mathbf{a b}^{+\cdot}$, respectively (Table 2 ). The vertical recombination energy in $\mathbf{2 a} \mathrm{a}^{\mathbf{2 +}}$ is greater than the ionization energy of Cs $(3.894 \mathrm{eV})$. Thus, electron transfer from $C$ s is exothermic by $\Delta E=4.96-3.89=1.07 \mathrm{eV}$, which is near-resonant with the G-excited state in $2 \mathbf{a}^{+\cdot}$ of $\Delta E_{\text {exc }}=1.09 \mathrm{eV}$ (Figure 7). Which of the $2 \mathbf{a a}^{+\cdot}$ and $2 \mathbf{a b}^{+\cdot}$ structures is going to develop from vertically formed $2 \mathbf{a}^{+\cdot}$ is difficult to predict. Therefore we have analyzed the relevant portions of the potential energy surface along the reaction pathways starting from both structures to investigate their intrinsic reactivity.

Structure $2 \mathbf{a a}^{+\cdot}$ has the radical center in the guanidine group, which may favor loss of guanidine, as reported for other arginine radicals [6, 9]. Loss of guanidine from $2 \mathrm{aa}^{+\cdot}$ is calculated to be only slightly endothermic to give ion $6^{+\cdot}$ or its conformers (Table 5, Scheme 4). Ion $2 \mathbf{a a}^{+\cdot}$ can undergo a slightly exothermic chain folding to form conformer $2 \mathrm{ac}^{+\cdot}$ (Scheme 4). This has a favorable arrangement of the $\mathrm{C}_{\alpha}-\mathrm{H}$ bond and guanidine radical group to reach TS4 for $\mathrm{H}$-atom transfer, which is at $E_{\mathrm{TS} 4}=30 \mathrm{~kJ} \mathrm{~mol}^{-1}$ above $2 \mathrm{aa}^{+}$. The $\mathrm{H}$-atom transfer is substantially exothermic when combined with conformational relaxation and proton transfer to the basic triaminomethyl group to form $\mathrm{C}_{\alpha}$-radical $2 \mathrm{ad}^{+}$. The transition states for the proton transfer and associated conformational transformations in the interme- 


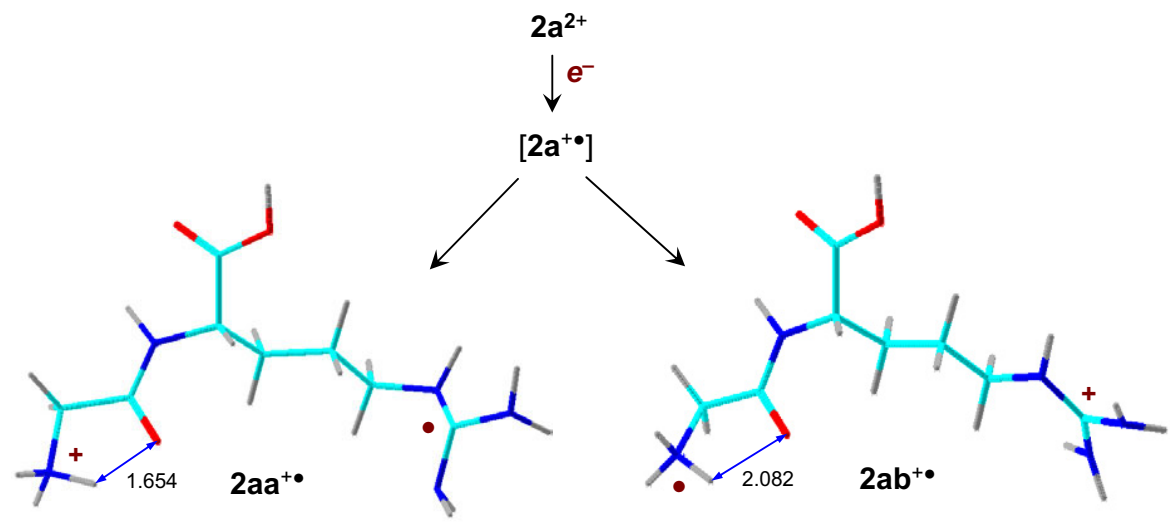

Scheme 3

diates were not studied. $\mathrm{C}_{\alpha}$-radical $2 \mathrm{ad}^{+\cdot}$ can further undergo facile loss of ammonia from the triaminomethylgroup to give ion $7 \mathrm{a}^{+\cdot}$ or its more stable conformers $\left(7 \mathrm{~b}^{+\cdot}\right.$, Scheme 4).

Structure $2 \mathbf{a b}^{+\cdot}$ can stabilize by forming a hydrogen bond between the charged guanidinium and $\mathrm{COOH}$ groups. Interestingly, this was accompanied by spontaneous and exothermic isomerization by $\mathrm{Gly}-\mathrm{NH}_{3}$ proton migration to form enolimine $2 \mathbf{a e}^{+\cdot}$ Scheme 5 ). Interestingly, this pathway is convergent with charge reduction in

Table 5. Relative and dissociation energies of $(\mathrm{GR}+2 \mathrm{H})^{+}$ cation-radicals

\begin{tabular}{|c|c|c|c|c|}
\hline \multirow[b]{3}{*}{ Species/reaction } & \multicolumn{4}{|c|}{ Relative energy ${ }^{a, b}$} \\
\hline & \multicolumn{2}{|c|}{$6-31++G(d, p)$} & \multicolumn{2}{|c|}{$6-311++G(2 d, p)$} \\
\hline & B3LYP & B3LYP & PMP2 & B3-PMP2 \\
\hline $2 \mathrm{aa}^{+\cdot} \rightarrow 2 \mathrm{ab}^{+\cdot}$ & -2 & 0.3 & 53 & 27 \\
\hline $2 \mathrm{aa}^{+\cdot} \rightarrow 2 \mathrm{ac}^{+\cdot}$ & -2 & 0.1 & -9 & -5 \\
\hline $2 \mathrm{aa}^{+\cdot} \rightarrow \mathrm{TS} 4$ & 31 & 35 & 24 & 30 \\
\hline $2 \mathrm{aa}^{+\cdot} \rightarrow 2 \mathrm{ad}^{+\cdot}$ & -98 & -93 & -102 & -98 \\
\hline $2 \mathrm{aa}^{+\cdot} \rightarrow 2 \mathrm{ae}^{+\cdot}$ & -80 & -77 & -74 & -75 \\
\hline $2 \mathrm{aa}^{+\cdot} \rightarrow \mathrm{TS} 5$ & -47 & -46 & -24 & -35 \\
\hline $\begin{array}{l}2 \mathbf{a a}^{+\cdot} \rightarrow z^{+\cdot}+ \\
\quad \mathrm{H}_{2} \mathrm{NCH}_{2} \mathrm{C}(\mathrm{OH})=\mathrm{NH}\end{array}$ & -84 & -89 & -47 & -68 \\
\hline $\begin{array}{l}2 \mathbf{a a}^{+\cdot} \rightarrow \mathbf{6}^{+\cdot}+ \\
\left(\mathrm{H}_{2} \mathrm{~N}\right)_{2} \mathrm{C}=\mathrm{NH}\end{array}$ & 0.2 & 7 & 29 & 18 \\
\hline $2 \mathrm{aa}^{+\cdot} \rightarrow 7 \mathrm{a}^{+\cdot}+\mathrm{NH}_{3}$ & -21 & -28 & 6 & -11 \\
\hline $7 a^{+\cdot} \rightarrow 7 b^{+}$ & -39 & -39 & -40 & -40 \\
\hline $2 \mathrm{aa}^{+\cdot} \rightarrow 2 \mathrm{af}^{+\cdot}$ & -58 & -55 & -57 & -56 \\
\hline $2 \mathrm{aa}^{+\cdot} \rightarrow 2 \mathrm{ag}^{+\cdot}$ & -212 & -210 & -210 & -210 \\
\hline $2 \mathrm{aa}^{+\cdot} \rightarrow \mathbf{8}^{+\cdot}+\mathrm{NH}_{3}$ & -172 & -175 & -164 & -169 \\
\hline $2 \mathrm{aa}^{+\cdot} \rightarrow \mathrm{TS} 6$ & -62 & -57 & -63 & -60 \\
\hline $2 \mathrm{aa}^{+\cdot} \rightarrow 2 \mathrm{ah}^{+\cdot}$ & -96 & -91 & -93 & -92 \\
\hline $2 \mathrm{aa}^{+\cdot} \rightarrow \mathrm{TS7}$ & -50 & -46 & -34 & -40 \\
\hline $2 \mathrm{aa}^{+\cdot} \rightarrow 2 \mathrm{ai}^{+\cdot}$ & -150 & -151 & -132 & -141 \\
\hline $2 \mathrm{aa}^{+\cdot} \rightarrow 2 \mathrm{ba}^{+\cdot}$ & -17 & -12 & 20 & 4 \\
\hline $2 \mathrm{ba}^{+\cdot} \rightarrow 2 \mathrm{ae}^{+\cdot}$ & -63 & -65 & -94 & -79 \\
\hline $2 \mathrm{aa}^{+\cdot} \rightarrow 2 \mathrm{ca}^{+\cdot}$ & -88 & -85 & -73 & -79 \\
\hline $2 \mathrm{ca}^{+\cdot} \rightarrow$ TS8 & 3 & 3 & 7 & 5 \\
\hline $\begin{array}{l}\mathbf{2} \mathbf{c a}^{+\cdot} \rightarrow \mathbf{z}^{+\cdot}+ \\
\quad \mathrm{H}_{2} \mathrm{NCH}_{2} \mathrm{C}(\mathrm{OH})=\mathrm{NH}\end{array}$ & 4 & -4 & 27 & 11 \\
\hline
\end{tabular}

an units of $\mathrm{kJ} \mathrm{mol}^{-1}$.

bIncluding B3LYP/6-31++G(d,p) zero-point energies and referring to $0 \mathrm{~K}$. ion conformer $2 \mathbf{b}^{\mathbf{2 +}}$, which produces cation-radical $\mathbf{2} \mathbf{b a} \mathbf{a}^{+}$. as a local energy minimum (Scheme 5). The recombination energies for $\mathbf{2} \mathbf{b}^{\mathbf{2 +}}$ were calculated as $\mathrm{RE}_{\mathrm{v}}=5.31 \mathrm{eV}$ and $\mathrm{RE}_{\mathrm{a}}=5.62 \mathrm{eV}$ (Table 2). The unpaired electron and charge distribution in $\mathbf{2} \mathbf{b a}^{+\cdot}$ is similar to that in $\mathbf{2} \mathbf{a b}^{+\cdot}$ in that the charge is carried by the planar guanidinium group, whereas the spin density is partitioned at 35\% in the Gly ammonium, $40 \%$ in the Gly amide, and $20 \%$ in the $\mathrm{COOH}$ group. Ion $\mathbf{2} \mathbf{b a}^{+\cdot}$ can exothermically isomerize to $2 \mathbf{a e}^{+\cdot}$ by Gly $\mathrm{NH}_{3}$ proton migration. The latter isomer can break the $\mathrm{N}-\mathrm{C}_{\alpha}$ bond in TS5, which is $62 \mathrm{~kJ} \mathrm{~mol}^{-1}$ below $2 \mathbf{a b}^{+\cdot}$ and $40 \mathrm{~kJ} \mathrm{~mol}^{-1}$ above $2 \mathrm{ae}^{+\cdot}$, to form a Gly enolimine neutral fragment and the $z^{+\cdot}$ ion at $7 \mathrm{~kJ} \mathrm{~mol}^{-1}$ above $2 \mathrm{ae}^{+\cdot}$ (Scheme 5).

Another side-chain rotation in $2 \mathbf{a b}^{+\cdot}$ brings the charged guanidinium group close to the Gly amide in $\mathbf{2 a f}^{+\cdot}$, which is $83 \mathrm{~kJ} \mathrm{~mol}^{-1}$ more stable than $2 \mathbf{a b}^{+\cdot}$ (Table 5, Scheme 6). An interesting feature of $2 \mathbf{a f}^{++}$is the shift of unpaired electron density from the Gly ammonium to the amide group, which shows substantial pyramidization and carries much of the spin density $(84 \%)$, whereas the ammonium group carries only $5 \%$. Ion $\mathbf{2} \mathrm{af}^{+\cdot}$ can undergo two dissociations. One is a highly exothermic elimination of the Gly ammonia $\left(8^{+\cdot}\right)$ forming first an ion-molecule complex $2 \mathrm{ag}^{+\cdot}$. Although we did not study the transition state for the ammonia elimination from $2 \mathbf{a f}^{+\cdot}$, previous calculations on similar Gly-N-terminated peptide cation radicals found extremely low TS energies for this dissociation [10, 25, 26]. The other pathway involves ammonium proton migration onto the Gly-amide carbonyl through TS6 to form enolimine $\mathbf{2} \mathbf{a h}^{+\cdot}$, which is isomeric with $2 \mathbf{a e}^{+\cdot}$ shown in Scheme 5. The TS6 energy is slightly below that of $\mathbf{2} \mathbf{a f}^{+}$. because of the zero-point energy decrease in the transition state. This indicates a practically barrierless and exothermic isomerization of $2 \mathbf{a f}^{+\cdot}$ to $2 \mathbf{a h}^{+\cdot}$. An $\mathrm{N}-\mathrm{C}_{\alpha}$ bond cleavage in $2 \mathrm{ah}^{+\cdot}$ proceeds through another lowlying TS7 (67 $\mathrm{kJ} \mathrm{mol}^{-1}$ below $2 \mathrm{ab}^{+\cdot}$ ) to form ionmolecule complex 2ai ${ }^{+\cdot}$ (Scheme 6). The latter can dissociate to Gly enolimine and the $z^{+\cdot}$ ion. In the course of the dissociation, complex $2 \mathbf{a i}^{+\cdot}$ may undergo further conformational transformations to achieve a 


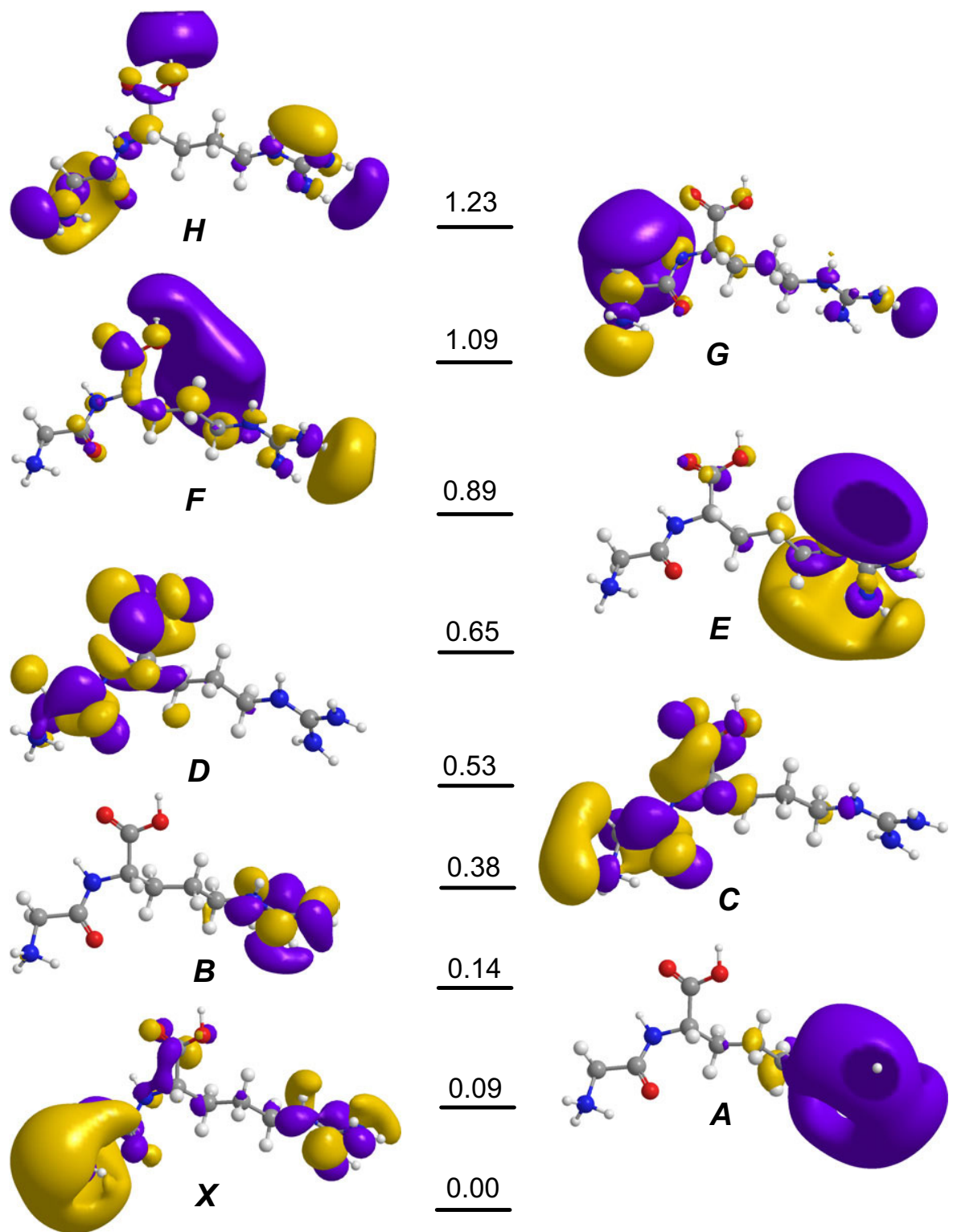

Figure 7. Electronic states and molecular orbitals in vertically reduced $2 \mathrm{a}^{+\cdot}$ from TD-B3LYP/ $6-311++\mathrm{G}(2 \mathrm{~d}, \mathrm{p})$ calculations. Excitation energies are given in $\mathrm{eV}$. The orbital phases are distinguished by gold and purple color.

favorable H-bonding arrangement in the incipient $z^{+\cdot}$ ion. Another intermediate step that would further lower the energy threshold for the products may involve prototropic isomerization of neutral glycine enolimine to the more stable glycine amide. Whether or not these isomerizations occur is unclear because the ECID spectra did not provide information on the neutral and ion fragment structures.

Nevertheless, the calculated energies in Tables 2 and 5 indicate that $2 \mathbf{a i}^{+\cdot}$ accumulated very high vibrational excitation through exothermic electron-transfer from Cs $\left(\Delta E_{\text {exc }}=182 \mathrm{~kJ} \mathrm{~mol}^{-1}\right)$ and isomerization of the primary charge-reduced structure $2 \mathbf{a b}^{+\cdot}$ on the potential energy surface $\left(168 \mathrm{~kJ} \mathrm{~mol}^{-1}\right)$. Thus, although $2 \mathrm{ai}^{+\cdot}$ resides in a potential energy well and its dissociation to glycine enolimine and the $z^{+\cdot}$ ion is $73 \mathrm{~kJ} \mathrm{~mol}^{-1}$ endothermic, this noncovalent binding energy is insufficient to prevent dissociation on the experimental timescale (see following text).

Finally, electron capture in $2 \mathrm{c}^{2+}$ was accompanied by spontaneous migration of the Gly ammonium proton to form enolimine $2 \mathrm{ca}^{+\cdot}$ (Scheme 7). Attempts at capturing the putative $2 \mathrm{c}^{+\cdot}$ cation-radical having a Gly amide group were unsuccessful. Even when starting the geometry optimization with structures that had puckered guanidinium groups, which is a structure feature typical for Arg-based radicals [6, 9], the optimized structures converged to $2 \mathrm{ca}^{+}$. The adiabatic recombination energy of $2 \mathrm{c}^{2+}$ was calculated as $6.59 \mathrm{eV}$, which includes the substantial exothermicity in the isomerization of vertically reduced $2 \mathrm{c}^{2+}$ to $2 \mathrm{ca}^{+\cdot}$. The vertical recombination energy in $2 \mathrm{c}^{2+}$ is $\mathrm{RE}_{\mathrm{v}}=5.29 \mathrm{eV}$ (Table 2). Ion $2 \mathrm{ca}^{+\cdot}$ can undergo 


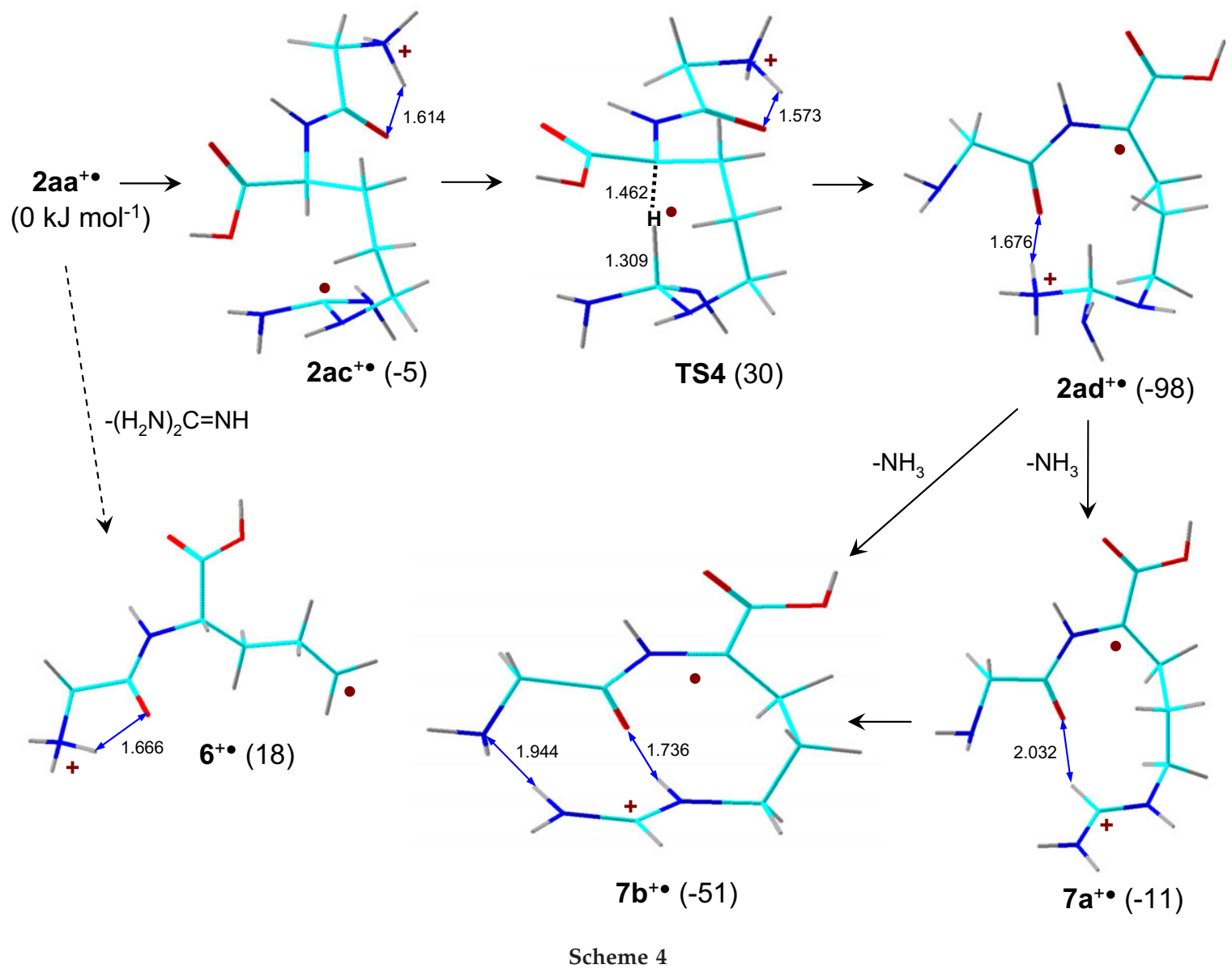

a very facile $\mathrm{N}-\mathrm{C}_{\alpha}$ bond cleavage via TS8, which is only $5 \mathrm{~kJ} \mathrm{~mol}^{-1}$ above $2 \mathrm{ca}^{+\cdot}$. The spontaneous formation of the enolimine intermediate $2 \mathbf{c a}^{+\cdot}$ and the low TS energy for the $\mathrm{N}-\mathrm{C}_{\alpha}$ bond cleavage in this conformer are likely to steer the dissociation to form the $z^{+\cdot}$ ion as a practically exclusive dissociation.

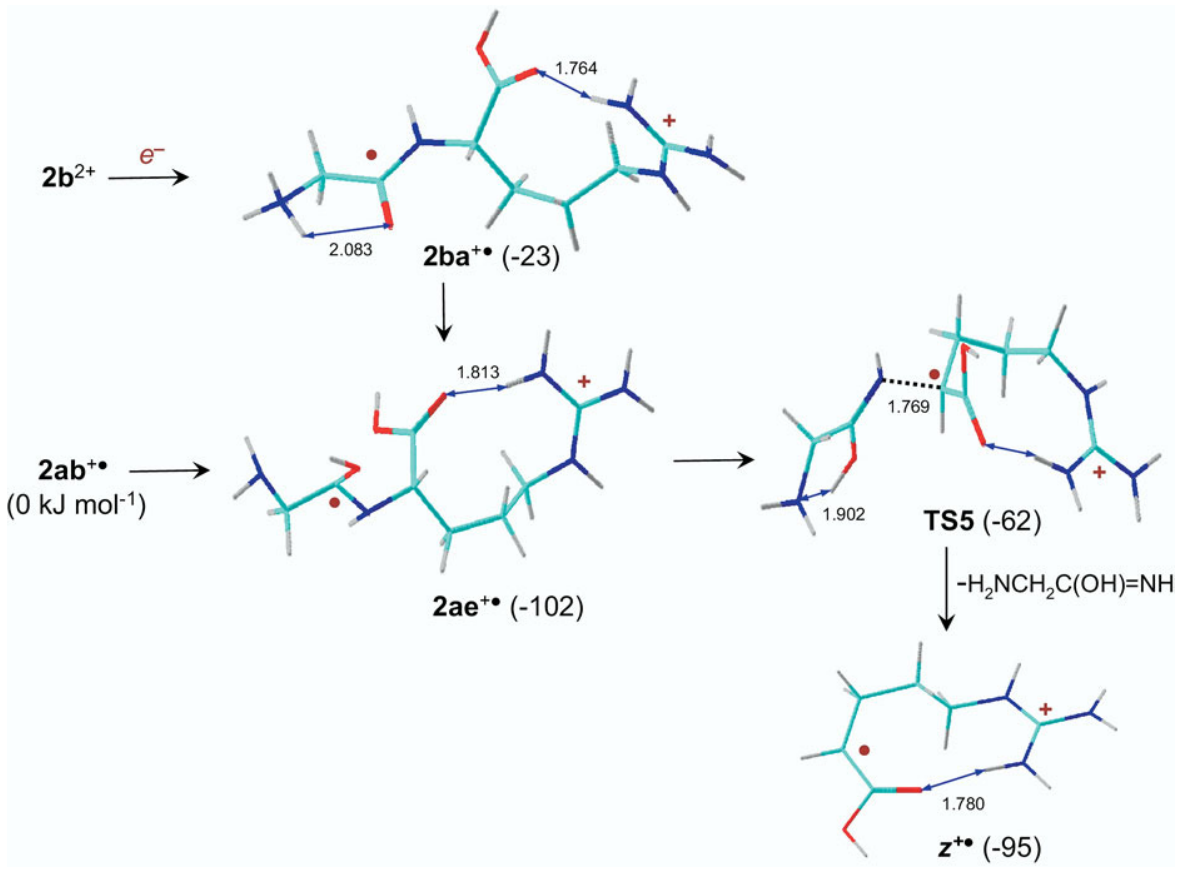

Scheme 5 


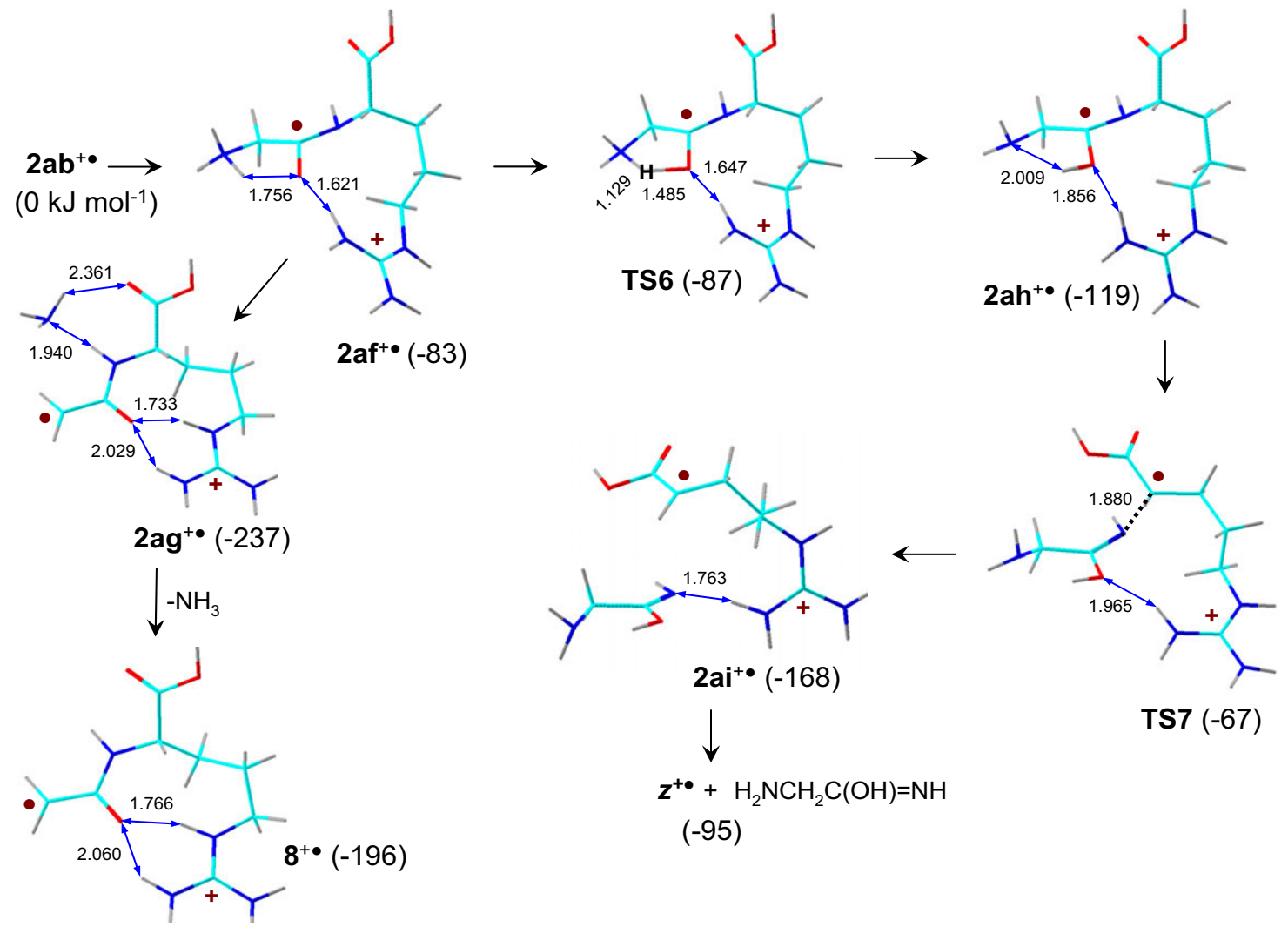

Scheme 6

\section{Discussion}

The mass spectra and calculations point to very different reactivity and electronic structures of radicals formed by electron transfer to singly and doubly protonated peptides containing C-terminal arginine residues. Both $(\mathrm{GR}+\mathrm{H})^{\cdot}$ and $(\mathrm{GR}+2 \mathrm{H})^{+\cdot}$ undergo $\mathrm{N}-\mathrm{C}_{\alpha}$ bond dissociations, resulting in the formation of $z$-type fragments. However, major differences are observed in the kinetic stability of the radical species formed by electron transfer whereby substantial fractions of nondissociating $(\mathrm{GR}+\mathrm{H})^{\prime}$ and $(\mathrm{AR}+\mathrm{H})$ were detected, whereas $(\mathrm{GR}+2 \mathrm{H})^{+\cdot}$ and $(\mathrm{AR}+2 \mathrm{H})^{+\cdot}$ completely dissociated. These differences arise from both different timescales for dissociations in ECID and $C R$, different energies in the intermediates, and the electronic properties of the charge-reduced intermediates. We now discuss these topics in some detail.

Dissociations of $(\mathrm{GR}+\mathrm{H})$ and $(\mathrm{AR}+\mathrm{H})$ ' radicals are confined to occur within the collision cell to allow the formation of anions to be observed. It follows from Pois-

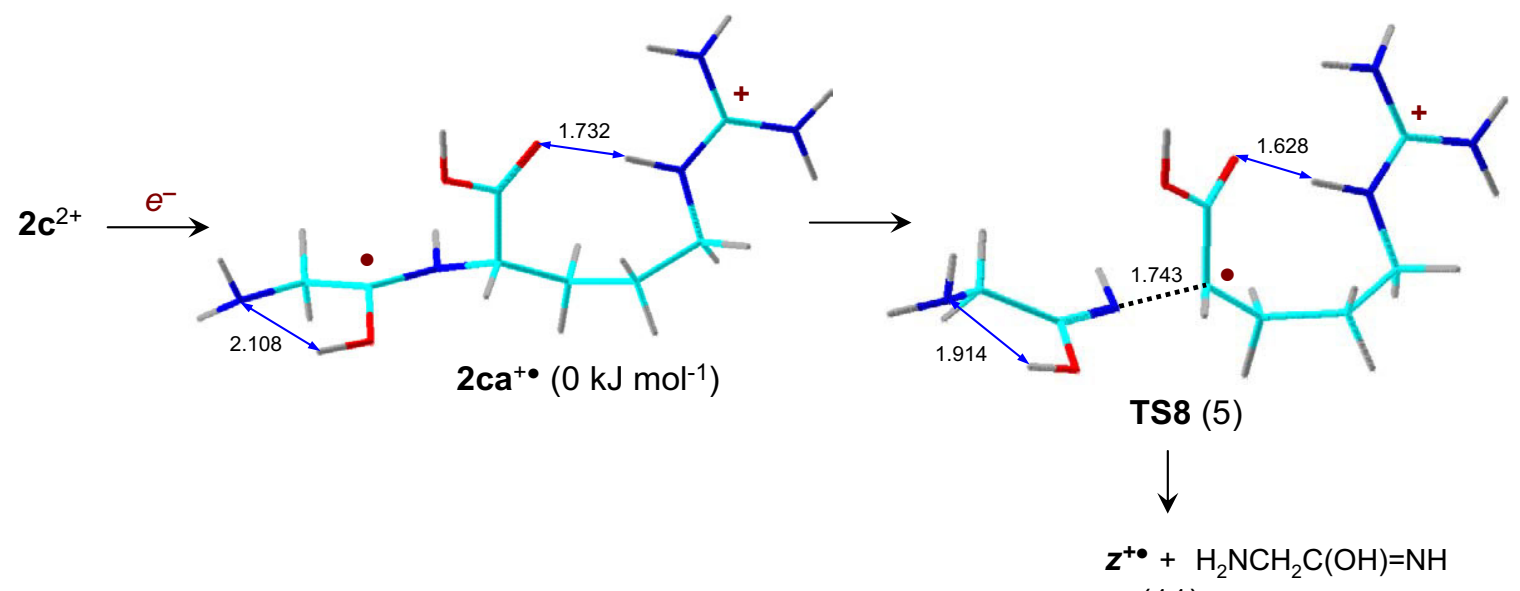

(11) 
son statistics that for electron transfer in two consecutive collisions with Cs, cation $\rightarrow$ radical and radical $\rightarrow$ anion [37], the latter is most likely to be formed in the second half of the collision cell [6]. Thus, with the ion flight time through the cell being about 200 ns, the most probable lifetime for radicals to be ionized is about 100 ns. In contrast, cation-radicals produced by ECID are observed after traveling to the detector at about $1.5 \mathrm{~m}$ distance from the cell, which requires they had lifetimes of about $5 \mu \mathrm{s}$. This 50-fold difference in radical and cation-radical lifetimes prefers detection of short-lived radicals with dissociation rate constants of $k \leq 2 \times 10^{7} \mathrm{~s}^{-1}$, whereas detectable cation-radicals must have $k \leq 5 \times 10^{5} \mathrm{~s}^{-1}$, both to allow detection of $10 \%$ nondissociating species.

The second factor is the different energetics of electron transfer. It follows from the comparison of the ion recombination energies that electron transfer from Cs is about $1 \mathrm{eV}$ endoergic for the monocations and about 1.1-1.3 eV exoergic for the dications. Since the $\mathrm{Cs}^{+}$ cation has only high-lying electronic states, the excess energy from exoergic electron-transfer collision is likely to be deposited in the charge-reduced ion to drive its dissociations.

Substantial differences are also found for the electronic structure and potential energy surfaces of the $(\mathrm{GR}+\mathrm{H})^{\cdot}$ radicals and $(\mathrm{GR}+2 \mathrm{H})^{+\cdot}$ cation-radicals. The former are unambiguously characterized as guanidinium radicals in their ground electronic states, which prefer isomerizations via $\mathrm{H}$-atom migrations, e.g., through TS2 in $(\mathrm{GR}+\mathrm{H})$. In contrast, electron transfer to $(\mathrm{GR}+2 \mathrm{H})^{2+}$ conformers produces multiple electronic states that differ in electron distribution and reactivity. For example, loss of ammonia from (GR + $2 \mathrm{H})^{+\cdot}$ can occur from the Gly residue in ion $2 \mathrm{af}^{+\cdot}$ or from the charged guanidinium group in $2 \mathrm{ad}^{+}$. These dissociations are triggered by the formation of a particular electronic state of charge reduced $2 a^{2+}$, e.g., $2 \mathbf{a b}^{+}$. for the former and $2 \mathbf{a a}^{+\cdot}$ for the latter. Specific ${ }^{15} \mathrm{~N}$ isotope labeling of the Gly, Ala, or Arg residues [27] would be necessary to establish which of these mechanisms operates in ECID. Multiple reaction pathways were also found by computations for the $\mathrm{N}-\mathrm{C}_{\alpha}$ bond dissociations in $(\mathrm{GR}+2 \mathrm{H})^{+}$, e.g., TS5, TS7, and TS8, that started from different precursor ion conformers and proceeded via different charge-reduced intermediates. In addition to the peptide dissociations that are typical for electron-based methods (loss of $\mathrm{H}, \mathrm{NH}_{3}$, guanidine, side-chain fragmentations, and $\mathrm{N}-\mathrm{C}_{\alpha}$ bond cleavage) [2]; the ECID spectra also showed loss of a $\mathrm{CH}_{3} \mathrm{~N}_{2}$ radical from the Arg side chain. The mechanism of this dissociation and the product ion structure are unknown now and may warrant further investigations.

\section{Conclusions}

Collisional electron transfer to $(\mathrm{GR}+\mathrm{H})^{+},(\mathrm{GR}+2 \mathrm{H})^{2+}$, and their $\mathrm{AR}$ homologues results in different dissociations of the charge-reduced intermediates. $(\mathrm{GR}+\mathrm{H})^{\cdot}$ radicals are initially formed as a conformationally homogeneous population that rapidly develops into several conformers that undergo competitive loss of guanidine, $\mathrm{N}-\mathrm{C}_{\alpha}$ bond dissociation, and rearrangement to $\mathrm{Arg}-\mathrm{C}_{\alpha}$ radicals. The latter are kinetically stable to be detected as anions. The $(\mathrm{GR}+2 \mathrm{H})^{+\cdot}$ cation radicals are formed as various conformers whose reactivity depends on the electron density distribution to drive competitive loss of ammonia and $\mathrm{N}-\mathrm{C}_{\alpha}$ bond cleavage. Multiple transition states were found for $\mathrm{N}-\mathrm{C}_{\alpha}$ bond cleavage in $(\mathrm{GR}+2 \mathrm{H})^{+\cdot}$ cation radicals that differed in charge distribution and conformations. This detailed study has revealed substantial complexity even in a relatively simple system and thus has led to the conclusion that multiple mechanisms for backbone cleavage dissociations may also operate in larger peptide ions after charge reduction by electron capture or transfer.

\section{Acknowledgments}

Research at University of Washington has received support from the National Science Foundation through Grants CHE-0750048 for experiments and CHE-0342956 for computations. The Department of Chemistry Computer Facility has been jointly supported by the NSF and University of Washington. F.T. thanks Dr. Julia ChamotRooke for the generous gift of a Gly-Arg sample and the Department of Physics and Astronomy at the University of Aarhus, Denmark, for a Visiting Professor fellowship in June-August 2007 during which the above-described experiments were carried out. Research at University of Aarhus was supported by the Danish Natural Research Council (Grants 21-04-0514 and 272-06-0427), Carlsbergfondet (Grant 2006-01-0229), and Lundbeckfonden.

\section{References}

1. Wysocki, V. H.; Tsapralis, G.; Smith, L. L.; Breci, L. A. Mobile and Localized Protons: A Framework for Understanding Peptide Dissociation. J. Mass Spectrom. 2000, 35, 1399-1406.

2. (a) Cooper, H. J.; Hudgins, R. R.; Hakansson, K.; Marshall, A. G. The Role of Electron Capture Dissociation in Biomolecular Analysis. J. Am. Soc. Mass Spectrom. 2002, 13, 241-249. (b) Cooper, H. J. Investigation of the Presence of $\mathrm{b}$ Ions in Electron Capture Dissociation Mass Spectra. J. Am. Soc. Mass Spectrom. 2005, 16, 1932-1940.

3. (a) Fung, Y. M. E.; Duan, L.; Chan, T. W. D. A Comparative Study of the Collision-Induced Dissociation and the Electron Capture Dissociation of Model Peptides Using Electrospray Ionization Fourier-Transform Mass Spectrometry. Eur. J. Mass Spectrom. 2004, 10, 449-457. (b) Xia, Y.; Gunawardena, H. P.; Erickson, D. E.; McLuckey, S. A. Effects of Cation Charge-Site Identity and Position on Electron-Transfer Dissociation of Polypeptide Cations. J. Am. Chem. Soc. 2007, 129, 12232-12243. (c) Fung, Y. M. E.; Chan, T. -W. D. Experimental and Theoretical Investigations of the Loss of Amino Acid Side Chains in Electron Capture Dissociation of Model Peptides. J. Am. Soc. Mass Spectrom. 2005, 16, 1523-1535.

4. Zubarev, R. A.; Kelleher, N. L.; McLafferty, F. W. Electron Capture Dissociation of Multiply Charged Protein Cations. A Nonergodic Process. J. Am. Chem. Soc. 1998, 120, 3265-3266.

5. Syka, J. E. P.; Coon, J. J.; Schroeder, M. J.; Shabanowitz, J.; Hunt, D. F. Peptide and Protein Sequence Analysis by Electron Transfer Dissociation Mass Spectrometry. Proc. Natl. Acad. Sci. U. S. A. 2004, 101, 9528-9533.

6. Hayakawa, S.; Matsubara, H.; Panja, S.; Hvelplund, P.; Nielsen, S. B.; Chen, X.; Tureček, F. Experimental Evidence for an Inverse Hydrogen Migration in Arginine Radicals. J. Am. Chem. Soc. 2008, 130, 7645-7654.

7. Hao, C.; Seymour, J. L.; Tureček, F. Electron Super-Rich Radicals in the Gas Phase. A Neutralization-Reionization Mass Spectrometric and Ab Initio/RRKM Study of Diaminohydroxymethyl and Triaminomethyl Radicals. J. Phys. Chem. A 2007, 111, 8829-8843.

8. (a) Yu, D.; Rauk, A.; Armstrong, D. A. Radicals and Ions of Glycine: An $\mathrm{Ab}$ Initio Study of the Structures and Gas-Phase Thermochemistry. J. Am. Chem. Soc. 1995, 117, 1789-1796. (b) Rauk, A.; Yu, D.; Armstrong, D. A. Toward Site Specificity of Oxidative Damage in Proteins: C-H and C-C Bond Dissociation Energies and Reduction Potentials of the Radicals of Alanine, Serine, and Threonine Residues-An Ab Initio Study. J. Am. Chem. Soc. 1997, 119, 208-217. (c) Block, D. A.; Yu, D.; Armstrong, D. A.; Rauk, A. On the Influence of Secondary Structure on the $\alpha-\mathrm{C}-\mathrm{H}$ Bond Dissociation Energy of Proline Residues in Proteins: A Theoretical Study. Can. J. Chem. 1998, 76, 1042-1049. (d) Rauk, A.; Yu, D.; Taylor, J.; 
Shustov, G. V.; Block, D. A.; Armstrong, D. A. Effects of Structure on $\alpha-\mathrm{C}-\mathrm{H}$ Bond Enthalpies of Amino Acid Residues: Relevance to $\mathrm{H}$ Transfers in Enzyme Mechanisms and in Protein Oxidation. Biochemistry 1999, 38, 9089-9096. (e) Reid, D. L.; Armstrong, D. A.; Rauk, A.; von Sonntag, C. H-Atom Abstraction by Thiyl Radicals from Peptides and Cyclic Dipeptides. A Theoretical Study of Reaction Rates. Phys. Chem. Chem. Phys. 2003, 5, 3994-3999.

9. Chen, X.; Tureček, F. The Arginine Anomaly: Arginine Radicals Are Poor Hydrogen Atom Donors in Electron Transfer Induced Dissociations. J. Am. Chem. Soc. 2006, 128, 12520-12530.

10. Tureček, F. Chen, X. Hao, C. Where Does the Electron Go? Electron Distribution and Reactivity of Peptide Cation Radicals Formed by Electron Transfer in the Gas Phase. J. Am. Chem. Soc. 2008, 130, $8818-8833$.

11. (a) Boltalina, O. V.; Hvelplund, P.; Jørgensen, T. J. D.; Larsen, M. C. Larsson, M. O.; Sharoitchenko, D. A. Sørensen, M. Electron Capture by Fluorinated Fullerene Anions in Collisions with Xe Atoms. Phys. Rev. A 2000, 62, 023202/1-7. (b) Larsson, M. O.; Hvelplund, P.; Larsen, M. C.; Shen, H.; Cederquist, H.; Schmidt, H. T. Electron Capture and Energy Loss in $\sim 100 \mathrm{keV}$ Collisions of Atomic and Molecular Ions on C60. Int. J. Mass Spectrom. 1998, 177, 51-62.

12. Frisch, M. J.; Trucks, G. W.; Schlegel, H. B.; Scuseria, G. E.; Robb, M. A.; Cheeseman, J. R.; Montgomery, J. A., Jr.; Vreven, T.; Kudin, K. N. Burant, J. C.; Millam, J. M.; Iyengar, S. S.; Tomasi, J.; Barone, V.; Mennucci, B. Cossi, M. Scalmani, G.; Rega, N.; Petersson, G. A. Nakatsuji, H.; Hada, M.; Ehara, M.; Toyota, K.; Fukuda, R.; Hasegawa, J.; Ishida, M.; Nakajima, T.; Honda, Y.; Kitao, O.; Nakai, H.; Klene, M.; Li, X.; Knox, J. E.; Hratchian, H. P.; Cross, J. B.; Adamo, C.; Jaramillo, J.; Gomperts, R.; Stratmann, R. E.; Yazyev, O.; Austin, A. J.; Cammi, R.; Pomelli, C.; Ochterski, J., W.; Ayala, P. Y.; Morokuma, K.; Voth, G. A.; Salvador, P.; Dannenberg, J. J.; Zakrzewski, V. G.; Dapprich, S.; Daniels, A. D.; Strain, M. C.; Farkas, O.; Malick, D. K.; Rabuck, A. D.; Raghavachari, K.; Foresman, J. B.; Ortiz, J. V.; Cui, Q.; Baboul, A. G.; Clifford, S.; Cioslowski, J.; Stefanov, B. B.; Liu, G.; Liashenko, A.; Piskorz, P. Komaromi, I.; Martin, R. L.; Fox, D. J.; Keith, T.; Al-Laham, M. A.; Peng, C. Y.; Nanayakkara, A.; Challacombe, M.; Gill, P. M. W.; Johnson, B.; Chen, W.; Wong, M. W.; Gonzalez, C.; Pople, J. A. Gaussian 03, Revision B. 05; Gaussian, Inc.; Pittsburgh PA, 2003.

13. (a) Becke, A. D. A New Mixing of Hartree-Fock and Local DensityFunctional Theories. J. Chem. Phys. 1993, 98, 1372-1377. (b) Becke, A. D. Density Functional Thermochemistry. III. The Role of Exact Exchange. J. Chem. Phys. 1993, 98, 5648-5652.

14. Rauhut, G.; Pulay, P. Transferable Scaling Factors for Density Functional Derived Vibrational Force Fields. J. Phys. Chem. 1995, 99, 30933100 .

15. Møller, C.; Plesset, M. S. A Note on an Approximation Treatment for Many-Electron Systems. Phys. Rev. 1934, 46, 618-622.

16. (a) Schlegel, H. B. Potential Energy Curves Using Unrestricted MollerPlesset Perturbation Theory with Spin Annihilation. J. Chem. Phys. 1986, 84, 4530-4534. (b) Mayer, I. Spin-Projected UHF Method. IV. Comparison of Potential Curves Given by Different One-Electron Methods. Adv. Ouantum. Chem. 1980, 12, 189-262.

17. Tureček, F. Proton Affinity of Dimethyl Sulfoxide and Relative Stabilities of $\mathrm{C}_{2} \mathrm{H}_{6} \mathrm{OS}$ Molecules and $\mathrm{C}_{2} \mathrm{H}_{7} \mathrm{OS}^{+}$Ions. A Comparative G2(MP2) $\mathrm{Ab}$ Initio and Density Functional Theory Study. J. Phys. Chem. A. 1998, $102,4703-4713$

18. (a) Tureček, F. Wolken, J. K. Dissociation Energies and Kinetics of Aminopyrimidinium Radicals by $\mathrm{Ab}$ Initio and Density Functional Theory. J. Phys. Chem. A 1999, 103, 1905-1912. (b) Tureček, F.; Polášek, M.; Frank, A. J.; Sadílek, M. Transient Hydrogen Atom Adducts to Disulfides: Formation and Energetics. I. Am. Chem. Soc. 2000, 122 2361-2370. (c) Polášek, M.; Tureček, F. Hydrogen Atom Adducts to Nitrobenzene. Formation of the Phenylnitronic Radical in the Gas Phase and Energetics of Wheland Intermediates. J. Am. Chem. Soc. 2000, 122, 9511-9524. (d) Rablen, P. R. Is the Acetate Anion Stabilized by Resonance or Electrostatics? A Systematic Structural Comparison. I. Am. Chem. Soc. 2000, 122, 357-368. (e) Rablen, P. R. Computational Analysis of the Solvent Effect on the Barrier to Rotation about the Conjugated C-N Bond in Methyl N,N-Dimethylcarbamate. J. Org. Chem. 2000, 65, 7930-7937. (f) Rablen, P. R.; Bentrup, K. H. Are the Enolates of Amides and Esters Stabilized by Electrostatics? I. Am. Chem. Soc, 2003, 125 2142-2147. (g) Hirama, M.; Tokosumi, T.; Ishida, T.; Aihara, J. Possible
Molecular Hydrogen Formation Mediated by the Inner and Outer Carbon Atoms of Typical PAH Cations. Chem. Phys. 2004, 305, 307-316.

19. Rassolov, V. A.; Ratner, M. A.; Pople, J. A. Electron Correlation in Chemical Bonds. J. Chem. Phys. 2000, 112, 4014-4019.

20. Stratmann, R. E.; Scuseria, G. E.; Frisch, M. J. An Efficient Implementation of Time-Dependent Density Functional Theory for the Calculation of Excitation Energies of Large Molecules. J. Chem. Phys. 1998, 109, $8218-8224$

21. Reed, A. E.; Weinstock, R. B.; Weinhold, F. Natural Population Analysis. J. Chem. Phys. 1985, 83, 735-746.

22. Gilbert, R. G.; Smith, S. C. Theory of Unimolecular and Recombination Reactions; Blackwell Scientific Publications: Oxford, UK, 1990; pp 52-132.

23. Zhu, L.; Hase, W. L. General Program for Unimolecular Rate Constants. Quantum Chemistry Program Exchange; Indiana University: Bloomington, 1994; Program No. QCPE 644.

24. Frank, A. J. Sadílek, M.; Ferrier, J. G.; Tureček, F. Sulfur Oxyacids and Radicals in the Gas Phase. A Variable-Time Neutralization-PhotoexcitationReionization Mass Spectrometric and Ab Initio/RRKM Study. J. Am. Chem. Soc. 1997, 119, 12343-12353.

25. Tureček, F.; Syrstad, E. A. Hydrogen Atom Adducts to the Amide Bond Generation and Energetics of Amide Radicals in the Gas Phase. J. Am. Chem. Soc. 2003, 125, 3353-3369.

26. Tureček, F. N-C C Bond Dissociation Energies and Kinetics in Amide and Peptide Radicals. Is the Dissociation a Non-Ergodic Process? J. Am. Chem. Soc. 2003, 125, 5954-5963.

27. Holm, A. I. S.; Hvelplund, P.; Kadhane, U.; Larsen, M. K.; Liu, B. Nielsen, S. B.; Panja, S.; Pedersen, J. M.; Skrydstrup, T.; Støchkel, K.; Williams, E. R.; Worm, E. S. On the Mechanism of Electron-CaptureInduced Dissociation of Peptide Dications from 15N-Labeling and Crown-Ether Complexation. J. Phys. Chem. A 2007, 111, 9641-9643.

28. Hvelplund, P.; Liu, B.; Nielsen, S. Brøndsted; Panja, S. Poully, J.-C Støchkel, K. Electron Capture Induced Dissociation of Peptide Ions: Identification of Neutral Fragments from Secondary Collisions with Cesium Vapor. Int. J. Mass. Spectrom. 2007, 263, 66-70.

29. Hayakawa, S.; Hashimoto, M.; Matsubara, H.; Turecek, F. Dissecting the Proline Effect: Dissociations of Proline Radicals Formed by Electron Transfer to Protonated Pro-Gly and Gly-Pro Dipeptides in the Gas Phase. J. Am. Chem. Soc. 2007, 129, 7936-7949.

30. Harrison, A. G. The Gas-Phase Basicities and Proton Affinities of Amino Acids and Peptides. Mass Spectrom. Rev. 1997, 16, 201-217.

31. (a) Wolken, J. K.; Tureček, F. Modeling Nucleobase Radicals in the Gas Phase. Experimental and Computational Study of 2-Hydroxypyridinium and 2-(1H)Pyridone Radicals. J. Phys. Chem. A 1999, 103, 6268-6281. (b) Tureček, F. The Use of Kinetic Isotope Effects for the Determination of Internal Energy Distributions of Isolated Transient Species in the Gas Phase. Int. J. Mass Spectrom. 2003, 227, 327-338.

32. (a) IUPAC Compendium of Chemical Technology, 2nd Ed.; 1997 (http:// goldbook.iupac.org/C01480.html). (b) Eliel, E. L. Stereochemistry of Car bon Compounds; McGraw-Hill: New York, 1962; pp. 151-152, 237-38.

33. Moran, D.; Jacob, R.; Wood, G. P. F.; Coote, M. L.; Davies, M. J.; O'Hair R. A. J.; Easton, C. J.; Radom, L. Rearrangements in Model Peptide-Type Radicals via Intramolecular Hydrogen-Atom Transfer. Helv. Chim. Acta 2006, 89, 2254-2272.

34. Chu, I. K.; Zhao, J.; Xu, M.; Siu, S. O.; Hopkinson, A. C.; Siu, K. W. M. Are the Radical Centers in Peptide Radical Cations Mobile? The Generation, Tautomerism, and Dissociation of Isomeric $\alpha$-CarbonCentered Triglycine Radical Cations in the Gas Phase. J. Am. Chem. Soc. 2008, 130, 7862-7872

35. Syrstad, E. A.; Tureček, F. Toward a General Mechanism of ElectronCapture Dissociation. J. Am. Soc. Mass Spectrom. 2005, 16, 208-224.

36. (a) Sobczyk, M.; Anusiewicz, I.; Berdys-Kochanska, J.; Sawicka, A.; Skurski, P.; Simons, J. Coulomb-Assisted Dissociative Electron Attachment: Application to a Model Peptide. J. Phys. Chem. A 2005, 109, 250-258. (b) Anusiewicz, I.; Berdys-Kochanska, J.; Skurski, P.; Simons, J. Simulating Electron Transfer Attachment to a Positively Charged Model Peptide. I. Phys. Chem. A 2006, 110, 1261-1266.

37. (a) Hayakawa, S. Charge Inversion Mass Spectrometry: Dissociation of Resonantly Neutralized Molecules. J. Mass Spectrom. 2004, 39, 111-135. (b) Hayakawa, S.; Kabuki, N. Dissociation Mechanism of Electronically Excited $\mathrm{CH}_{n}(n=3-5)$ Neutrals Formed by Near-Resonant Neutralization Using Charge Inversion Mass Spectrometry. Eur. Phys. J. D 2006, 38, 163-176. 